\title{
Cell Switch-Off Strategies for Green Mobile Networks
}

by

Furkan Alaca

B. Eng. in Communications Engineering, Carleton University,

Ottawa, Ontario, Canada, 2010

\begin{abstract}
A THESIS SUBMITTED TO THE
Faculty of Graduate and Postdoctoral Affairs

IN PARTIAL FULFILLMENT OF THE REQUIREMENTS FOR THE DEGREE OF

Master of Applied Science in Electrical Engineering
\end{abstract}

Ottawa-Carleton Institute for Electrical and Computer Engineering Department of Systems and Computer Engineering

Carleton University

Ottawa, Ontario

August 2012

(C) Furkan Alaca, 2012 
Library and Archives

Canada

Published Heritage

Branch

395 Wellington Street

Ottawa ON K1A ON4

Canada
Bibliothèque et

Archives Canada

Direction du

Patrimoine de l'édition

395 , rue Wellington

Ottawa ON K1A ON4

Canada
Your file Votre référence

ISBN: 978-0-494-93493-7

Our file Notre référence

ISBN: $978-0-494-93493-7$
NOTICE:

The author has granted a nonexclusive license allowing Library and Archives Canada to reproduce, publish, archive, preserve, conserve, communicate to the public by telecommunication or on the Internet, loan, distrbute and sell theses worldwide, for commercial or noncommercial purposes, in microform, paper, electronic and/or any other formats.

The author retains copyright ownership and moral rights in this thesis. Neither the thesis nor substantial extracts from it may be printed or otherwise reproduced without the author's permission.
AVIS:

L'auteur a accordé une licence non exclusive permettant à la Bibliothèque et Archives Canada de reproduire, publier, archiver, sauvegarder, conserver, transmettre au public par télécommunication ou par l'Internet, prêter, distribuer et vendre des thèses partout dans le monde, à des fins commerciales ou autres, sur support microforme, papier, électronique et/ou autres formats.

L'auteur conserve la propriété du droit d'auteur et des droits moraux qui protege cette thèse. $\mathrm{Ni}$ la thèse ni des extraits substantiels de celle-ci ne doivent être imprimés ou autrement reproduits sans son autorisation.
In compliance with the Canadian Privacy Act some supporting forms may have been removed from this thesis.

While these forms may be included in the document page count, their removal does not represent any loss of content from the thesis.
Conformément à la loi canadienne sur la protection de la vie privée, quelques formulaires secondaires ont été enlevés de cette thèse.

Bien que ces formulaires aient inclus dans la pagination, il n'y aura aucun contenu manquant. 


\begin{abstract}
The energy consumption of mobile networks is rapidly growing as operators deploy increasingly dense networks of base stations (BSs). This has resulted in an increased focus on improving energy efficiency. A major energy saving opportunity lies in being able to switch off cells during periods of light traffic.

One approach for constructing the cell switch-off problem is to define a minimum rate requirement for each user terminal (UT). Niu et al. follow this approach in [1], but omit inter-cell interference. We also construct our problem using the minimum rate requirement approach, but explore more realistic interference scenarios. We start by formulating an optimization problem using a constant interference model and find the optimal solution, for networks that are not very large, using binary integer linear programming (BILP). For larger networks, we improve the "cell zooming" (CZ) heuristic from [1] to bring it closer to the optimal solution; we call this "enhanced cell zooming" (ECZ). We then develop a more realistic construction of the problem by allowing interference to be a function of the active cells. The resulting complexity makes it extremely difficult to find the optimal solution through conventional optimization approaches. We built upon our ECZ heuristic to develop a scheme which takes into account the reduction in interference when cells are switched off. This interference-awareness allows a greater number of cells to be switched off when compared to the worst-case constant interference scenarios. Finally, we construct a genetic algorithm (GA) for the problem, and show that it yields considerable gains in energy savings under a wide range of test scenarios. We also show that our GA is able to save more energy while achieving lower blocking probability in the network.
\end{abstract}




\section{Acknowledgements}

First and foremost, I am most grateful to Allah (God), the Creator and Sustainer of the Universe, for giving me the ability to complete this work.

I wish to extend my special thanks to my supervisor, Dr. Halim Yanıkömeroğlu, for his support and guidance towards achieving the completion of this thesis. I would like to thank Akram Bin Sediq, a PhD student in our group, for his invaluable help and suggestions throughout my research. Thank you to Dr. Richard Yu, Dr. Rainer Schoenen, and Dr. Ramy Gohary for the feedback towards improving my work. My thanks are also due to Dr. Sebastian S. Szyszkowicz, with whom I have had the pleasure to work with throughout the course of my undergraduate and graduate studies. My thanks to the departmental staff for their administrative and technical support. I would also like to thank all of my friends with whom we studied together and encouraged one another throughout the course of our studies.

I am deeply grateful to my parents, Drs. Ayşe and Şaban Alaca, for raising me and for teaching me the most important things in life. A huge thanks to my sisters Zahide and Betül for their moral support and for always keeping me cheered up. 
Table of Contents

$\begin{array}{ll}\text { Abstract } & \text { ii }\end{array}$

Acknowledgements

Table of Contents $\quad$ iv

List of Tables $\quad$ vi

List of Figures vii

List of Acronyms $\quad$ ix

List of Symbols $\quad$ x

Chapter 1: Introduction $\quad 1$

1.1 Thesis Contributions . . . . . . . . . . . . . . . . . 3

1.2 Published Work . . . . . . . . . . . . . . . 5

1.3 Thesis Organization . . . . . . . . . . . . . . . . 5

$\begin{array}{lll}\text { Chapter 2: } & \text { Background and Literature Review } & 7\end{array}$

2.1 Research Challenges and Practical Issues in Cell Switch-Off . . . . . . 7

2.1.1 Network Planning . . . . . . . . . . . . . . . . 9 9

2.1.2 BS Configuration in Heterogeneous Networks . . . . . . . . . 9

2.1.3 UT Assignment . . . . . . . . . . . . . . . . . . 10

2.1.4 Cell Parameter Optimization . . . . . . . . . . . . . 10

2.1.5 Interference Management . . . . . . . . . . . . . . . 11

2.1.6 Time Scale . . . . . . . . . . . . . . . . . 11

2.1.7 User Traffic Prediction and Modeling . . . . . . . . . . . . 13

2.2 Tools for Developing Cell Switch-Off Schemes . . . . . . . . . . 13

2.2.1 Analytical Aspects . . . . . . . . . . . . . . 13

2.2.2 Problem-Specific Heuristics . . . . . . . . . . . . . . 14

2.2.3 Artificial Intelligence . . . . . . . . . . . . . . . . . 14

2.3 Overview of Genetic Algorithms . . . . . . . . . . . . . . 15

2.3.1 Initial Population . . . . . . . . . . . . . . . . . . 17

2.3.2 Chromosome Selection ............... 18

2.3.3 Crossover ..................... 19

2.3 .4 Mutation ................... 20

2.3 .5 Termination ...................... 20 
2.4 Related Work in Cell Switch-Off Algorithms . . . . . . . . . . . 21

2.4 .1 Cell Zooming . . . . . . . . . . . . . . . . . 21

2.4.2 Dynamic Base Station Energy Saving _ . . . . . . . . . 24

Chapter 3: Proposed Cell Switch-Off Schemes 26

3.1 Binary Integer Linear Programming Formulation $\ldots \ldots \ldots \ldots 27$

3.2 Enhanced Cell Zooming Heuristic . . . . . . . . . . . . . . . . . 29

3.3 Interference-Aware Cell Switch-Off Scheme . . . . . . . . . . . . 29

3.4 Genetic Algorithm Based Interference-Aware Cell Switch-Off Scheme 32

3.4.1 Chromosome Representation and Fitness Function . . . . . . 32

3.4 .2 Crossover Operators . . . . . . . . . . . . . . . . . 34

3.4 .3 Mutation ................... 36

3.4.4 Initial Population, Chromosome Selection, and Termination Conditions . . . . . . . . . . . . . . . . . 36

Chapter 4: $\quad$ Simulation System Model $\quad 37$

4.1 Channel and Interference Model . . . . . . . . . . . . . 38

4.2 Simulation Scenarios . . . . . . . . . . . . . . . . . . . . . . . . . . . 39

4.2 .1 Regular Hexagonal Layout . . . . . . . . . . . . . . . . . 39

4.2.2 Regular Hexagonal Layout with Varying Energy Consumption Levels . . . . . . . . . . . . . . . . . . . . . . 42

4.2 .3 Non-Regular Layout . . . . . . . . . . . . . . . . . . . 43

4.3 Wrap-Around . . . . . . . . . . . . . . . . 43

4.4 User Distribution and Traffic Model . . . . . . . . . . . . . . 45

Chapter 5: $\quad$ Simulation Results and Performance Analysis $\quad 49$

5.1 Results for Schemes with Constant Interference . . . . . . . . . . 49

5.2 Results for Schemes with Dynamic Interference . . . . . . . . . 50

5.3 Results with Variable Energy Consumption at BSs . . . . . . . . 55

5.4 Results for Springwald Layout _. . . . . . . . . . . . . 56

5.5 Trade-offs Between Energy Saving and User Satisfaction _. . . . . . 58

5.6 Implementation and Complexity . . . . . . . . . . . . 65

$\begin{array}{lll}\text { Chapter 6: } & \text { Conclusions and Future Work } & 67\end{array}$

6.1 Summary and Discussion of Contributions . . . . . . . . . . 67

6.2 Future Research Directions and Possible Extensions . . . . . . . . . 68

6.2.1 Cell Parameter Optimization . . . . . . . . . . . . . . . 68

6.2 .2 Advanced Radio Access Networks . . . . . . . . . . . . . . 69

6.2.3 Traffic Prediction and Machine Learning . . . . . . . . . . 69

6.2 .4 Parallel GAs . . . . . . . . . . . . . . . . . 70

6.2.5 Multiple Power States and Frequency Bands . . . . . . . . 70

6.2 .6 Larger Scale Simulation . . . . . . . . . . . . . . . 71

$\begin{array}{ll}\text { References } & \mathbf{7 2}\end{array}$ 


\section{List of Tables}

4.2.1 Summary of simulation parameters $[2] \ldots \ldots \ldots \ldots$

5.1.1 Simulation results with regular hexagonal cell layout with 57 cells and constant interference for uniform and hotspot UT distributions. Results represent the number of cells which were switched off. . . . . .

5.2.1 Simulation results with regular hexagonal cell layout with 57 cells and dynamic interference for uniform and hotspot UT distributions. Results represent the number of cells which were switched off. . . . . .

5.3.1 Simulation results with regular hexagonal cell layout with 57 cells, dynamic interference, and variable energy consumption for uniform and hotspot UT distributions. Results represent the energy saved relative to a single energy-efficient cell. . . . . . . . . . . . . . .

5.4.1 Simulation results with Springwald cell layout and dynamic interference for uniform and hotspot UT distribution. Results represent the number of cells which were switched off. . . . . . . . . . . . .

5.5.1 Trade-off between energy saving and user satisfaction with uniform distribution and average of 684 UTs in network. . . . . . . . .

5.5.2 Trade-off between energy saving and user satisfaction with hotspot distribution and average of 684 UTs in network. . . . . . . . .

5.5.3 Trade-off between energy saving and user satisfaction with uniform UT distribution and average of 361 UTs in network with Springwald cell layout with 57 cells. . . . . . . . . . . . . . . . .

5.5.4 Trade-off between energy saving and user satisfaction with hotspot UT distribution and average of 432 UTs in network with Springwald cell layout with 57 cells. 


\section{List of Figures}

1.0.1 Energy consumption break-down at a $3 \mathrm{G}$ BS with multi-carrier power

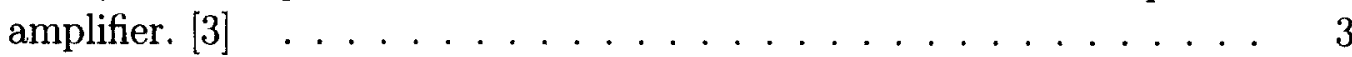

2.3.1 One-point crossover. . . . . . . . . . . . . . . . . 20

3.4.1 Partially matched crossover (figure taken from [4]). . . . . . . . . . 35

3.4.2 Example for order crossover. . . . . . . . . . . . . . . . . 35

4.2.1 Regular hexagonal layout, with arrows representing cells served by 120 degree sector antennas. . . . . . . . . . . . . . . . . . . . . 40 40

4.2.2 Springwald layout overlaid on a hexagonal grid, with black circles representing the BS locations. . . . . . . . . . . . . . . . . . . 44

4.2.3 Rogers cell site locations in downtown Montreal, denoted by the blue hexagons. . . . . . . . . . . . . . . . 45

4.3.1 Regular hexagonal cell layout with wrap-around. . . . . . . . . . 46

4.3.2 SINR curves without wrap-around. . . . . . . . . . . . . . . 47

4.3.3 SINR curves with wrap-around. . . . . . . . . . . . . 47

5.1.1 Plot of simulation results with regular hexagonal cell layout with 57 cells and constant interference for uniform UT distribution. Results represent the proportion of cells which were switched off. . . . . . .

5.1.2 Plot of simulation results with regular hexagonal cell layout with 57 cells and constant interference for hotspot UT distribution. Results represent the proportion of cells which were switched off. . . . . . .

5.2.1 Plot of simulation results with regular hexagonal cell layout with 57 cells and dynamic interference for uniform UT distribution. Results represent the proportion of cells which were switched off. . . . . . .

5.2.2 Plot of simulation results with regular hexagonal cell layout with 57 cells and dynamic interference for hotspot UT distribution. Results represent the proportion of cells which were switched off. . . . . . . 53

5.2.3 Plot showing IAGA convergence with an initial population of 57 . . .

5.3.1 Plot of simulation results with regular hexagonal cell layout with 57 cells, variable energy consumption, dynamic interference, and uniform UT distribution. Results represent the weighted proportion of cells switched off. 
5.3.2 Plot of simulation results with regular hexagonal cell layout with 57 cells, variable energy consumption, dynamic interference, and hotspot UT distribution. Results represent the weighted proportion of cells switched off.

5.4.1 Plot of simulation results with Springwald cell layout and dynamic interference for uniform UT distribution. Results represent the proportion of cells which were switched off. . . . . . . . . . . .

5.4.2 Plot of simulation results with Springwald cell layout and dynamic interference for hotspot UT distribution. Results represent the proportion of cells which were switched off. . . . . . . . . .

5.5.1 Plot of simulation results with a regular hexagonal layout for uniform UT distribution with 684 UTs. Results represent the proportion of users blocked as a function of the proportion of cells were switched off.

5.5.2 Plot of simulation results with a regular hexagonal layout for hotspot UT distribution with 684 UTs. Results represent the proportion of users blocked as a function of the proportion of cells were switched off

5.5.3 Plot of simulation results with Springwald cell layout with 57 cells for uniform UT distribution with 361 UTs. Results represent the proportion of users blocked as a function of the proportion of cells were switched off.

5.5.4 Plot of simulation results with Springwald cell layout with 57 cells for hotspot UT distribution with 432 UTs. Results represent the proportion of users blocked as a function of the proportion of cells were switched off. 


\section{List of Acronyms}

$\begin{array}{ll}\text { 4G } & \text { Fourth Generation } \\ \text { AI } & \text { Artificial Intelligence } \\ \text { ACO } & \text { Ant Colony Optimization } \\ \text { BILP } & \text { Binary Integer Linear Programming } \\ \text { BS } & \text { Base Station } \\ \text { CoMP } & \text { Coordinated Multiple Point Transmission and Reception } \\ \text { CZ } & \text { Cell Zooming } \\ \text { dB } & \text { Decibel } \\ \text { ECZ } & \text { Enhanced Cell Zooming } \\ \text { GA } & \text { Genetic Algorithm } \\ \text { HetNet } & \text { Heterogeneous Networks } \\ \text { IACZ } & \text { Interference-Aware Cell Zooming } \\ \text { IAGA } & \text { Interference-Aware Genetic Algorithm } \\ \text { ICIC } & \text { Inter-Cell Interference Coordination } \\ \text { MIMO } & \text { Multiple-Input Multiple-Output } \\ \text { RET } & \text { Remote Electrical Tilt } \\ \text { RWS } & \text { Roulette Wheel Selection } \\ \text { SNR } & \text { Signal to Noise Ratio } \\ \text { SINR } & \text { Signal to Interference and Noise Ratio } \\ \text { TS } & \text { Tournament Selection } \\ \text { UT } & \text { User Terminal }\end{array}$




\section{List of Symbols}

$\begin{array}{ll}P_{R X} & \text { transmitted power } \\ P_{T X} & \text { received power } \\ P L & \text { path loss } \\ A & \text { antenna pattern gain } \\ \alpha & \text { protection margin } \\ x_{i, j} & \text { binary variable such that } x_{i, j}=1 \text { if user } i \text { is connected to sector } j \\ y_{j} & \text { binary variable such that } y_{j}=1 \text { if sector } j \text { is active } \\ \rho_{i, j} & \text { spectral efficiency between user } i \text { and sector } j \\ B_{j} & \text { total bandwidth for sector } j \\ R_{i} & \text { minimum rate requirement for user } i \\ I & \text { number of users } \\ J & \text { number of sectors }\end{array}$ 


\section{Chapter 1}

\section{Introduction}

The mobile industry has experienced massive growth over the past decade. The introduction of smartphones and tablets, which combine cellular connectivity with powerful processing capabilities, has allowed the mobile application space to grow into areas such as social networking, online gaming, music and video streaming, online file storage, and other cloud-based services. Due to the scarcity of wireless spectrum, the most practical way for mobile operators to boost network capacity in order to serve this massive demand has been in aggressive frequency re-use through the deployment of more base stations (BSs). However, the rapidly growing number of BSs has contributed heavily to the growing energy consumption of cellular networks. In addition to the environmental concerns associated with the sharp rise in global energy consumption, energy consumption has also become a major component of operating expenditures (OPEX) for mobile network operators. Nokia-Siemens Networks, the world's number-two network equipment manufacturer, states in a 2011 article that energy consumption accounts for $13.5 \%$ of OPEX in mature markets and $26.3 \%$ in maturing markets [5]. Therefore, there is great interest in the research community towards reducing the overall energy consumption of cellular networks [6]. The BSs account for $65-75 \%$ of the total energy consumed by cellular networks $[5,7]$, and so one of the major energy saving opportunities for cellular networks lies in developing 
cell switch-off schemes which allow some cells to be switched off during non-peak periods.

As operators deploy greater numbers of BSs to fulfill their needs for higher capacity, cell sizes are reduced and therefore less transmit power is required to satisfy cell edge users. This allows for gains in energy efficiency, since power amplifiers account for upwards of $40 \%$ of a BS's total energy consumption [7]. Figure 1.0.1 shows the energy consumption break-down for a typical 3G BS as measured by Ericsson. However, there are still overhead energy costs in keeping a large number of BSs powered on at all times. Modern cellular networks are interference-limited (as opposed to noise-limited), and therefore in off-peak periods it can be possible to serve the same number of users with fewer BSs while keeping the transmit power fixed. Traffic-adaptive cellular networks could save energy by reconfiguring cell parameters and switching them on or off based on spatial and temporal fluctuations in network traffic. For example, business areas would experience higher traffic load than residential areas in the daytime, whereas the reverse would likely be true during evening hours. Since cellular networks are designed to meet demand during periods of heavy traffic, there will always be areas in the network which are underutilized throughout the day.

Mobile network operators are moving towards the deployment of a much greater number of small cells (namely femtocells, picocells, and microcells) as the most economically and technically feasible strategy to better service the rapidly growing demand for wireless traffic [8]. As mobile network architecture becomes more and more dominated by the presence of small cells, the motivation for developing cell switch-off schemes will grow stronger since the number of unutilized and underutilized cells at any given time of the day will undoubtedly increase. 


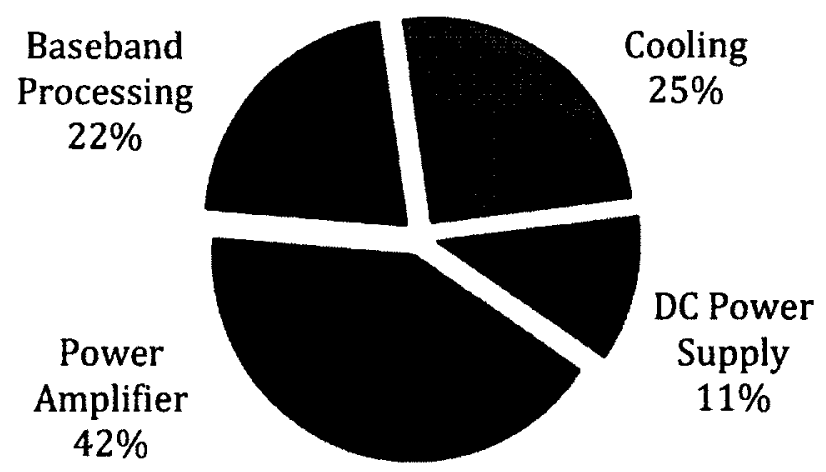

Figure 1.0.1: Energy consumption break-down at a 3G BS with multi-carrier power amplifier. [3]

\subsection{Thesis Contributions}

Cell switch-off is a difficult problem to solve when all parameters such as interference and quality of service requirements are taken into account. Other issues which arise in real-world deployments but are often not considered in existing research can complicate matters even further; examples include irregular cell layouts, user traffic and mobility models, cell-specific pathloss models, or differing parameters across cells such as transmit powers, antenna heights and downtilts, and energy consumption levels. Existing research makes various assumptions to simplify the problem and offers some heuristics to solve it. Niu et al. study the problem and develop a heuristic which they call "cell zooming" in [1] under the assumption that inter-cell interference coordination (ICIC) has been used to eliminate all interference in the network. We observe that even if ICIC is used, it can not fully eliminate interference and it also results in a reduction of the total bandwidth available for use in the network. We examine their heuristic in the context of a constant interference scenario, but we assume worst-case interference since this yields an achievable solution, whereas the assumption of no interference results in a high likelihood of yielding an unachievable 
solution in a real-world system.

Under the worst-case interference assumption, we formulate the cell switch-off problem mathematically using binary integer linear programming. This BILP formulation is equivalent to the bin-packing problem, which is NP-hard, if the spectral efficiency of each UT to all cells is fixed to a constant. Nonetheless, the formulation can be solved within seconds to find the optimal solution for scenarios with a relatively small number of users (about 9 users per cell with 57 cells). We compare the optimal solution with the "cell zooming" algorithm, and observe that there is a substantial performance gap. We then improve the heuristic to bring it closer to the optimal solution, which we call enhanced cell zooming.

Allowing the interference to be a function of the user assignment, which allows for a more realistic construction of the problem, increases the complexity of the problem (which, in the above case, is already NP-hard) even further and thereby necessitates a heuristic method. We built upon the enhanced cell zooming algorithm to address the variations in inter-cell interference which occur as a result of switching on and off different cells in the network. The results show that adding interference-awareness allows more flexibility in turning off a greater number of cells when compared with the worst-case interference scenarios. However, the optimal solution for the interferenceaware scenario is not known, due to the difficulty in formulating it mathematically as an optimization problem. In order to further improve the results, we formulated the problem as a genetic algorithm (GA). We analyze the performance of the above algorithms under different user distributions and when energy consumption varies across BSs. We also study the trade-off between energy saving and user satisfaction. We evaluated the algorithms using a non-regular cell layout as well, and found that our GA-based algorithm continued to perform well. 
The contributions of this thesis can be summarized as follows:

- We formulated and solved the cell switch-off problem with constant-interference as a BILP problem.

- We improved the heuristic from [1] and obtained substantial energy saving gains while maintaining linear complexity.

- We re-constructed the problem to allow interference to be a function of the UT assignment, and developed a heuristic to solve it. We showed that this interference-aware scheme can save dramatically more energy when compared to the worst-case (constant) interference scheme.

- We designed and implemented a GA for the interference-aware problem and obtained further improved results.

\subsection{Published Work}

- Furkan Alaca, Akram Bin Sediq, and Halim Yanikomeroglu, "A Genetic Algorithm Based Cell Switch-off Scheme for Energy Saving in Dense Cell Deployments", accepted for IEEE GLOBECOM'12, December 2012, Anaheim, California, USA.

\subsection{Thesis Organization}

The remainder of this thesis is organized as follows:

- Chapter 2: We review the existing work available in the literature which relates to cell switch-off and identify some associated research issues and challenges. 
We also give a brief overview of schemes which are related to our work, such as "cell zooming". We also describe GAs, which we later use in developing one of our schemes.

- Chapter 3: We describe in detail the schemes which we have developed. We start with the BILP formulation, which gives the optimal solution for the constant-interference scenario. Since BILP is computationally intensive, we aim to develop a heuristic which yields close to optimal results. We improve the "cell zooming" scheme from [1] to bring it closer to the optimal solution, which we call the enhanced cell zooming scheme. We then describe how we add interference-awareness to the enhanced cell zooming scheme, and describe how we develop a GA to obtain further improved results. We also describe how we select our parameters for the GA.

- Chapter 4: We give a detailed overview of how we built and evaluated the accuracy of our simulator, and describe our methodology for evaluating the performance of our schemes.

- Chapter 5: We present our simulation results, which show how much energy savings can be achieved through the schemes previously discussed. We also examine the trade-off between energy saving and user satisfaction.

- Chapter 6: We summarize our work and discuss some advantages, disadvantages, and limitations of the schemes which were presented. We also share some insights on future directions for this line of research. 


\section{Chapter 2}

\section{Background and Literature Review}

Green communications is a new research area to which contributions have been made by researchers specializing in many different aspects of telecommunications. Optimizing the energy efficiency of cellular networks requires work on many aspects such as software, hardware, and network planning and management. For example, electronic components such as power amplifiers need to be designed to be made more energy-efficient, and energy-saving protocols need to be designed at both the media access control (MAC) and network layers. Network planning also play a role in energy efficiency through the careful selection of cell sites, backhaul, cooling mechanisms, and even the use of alternative "off-grid" energy sources. A more exhaustive survey of research issues and challenges for green cellular networks can be found in [6].

\subsection{Research Challenges and Practical Issues in Cell Switch-Off}

One of the recently explored issues in green communications is the concept of selectively switching off BSs during periods of low network activity. This issue has been a discussion topic among industry members at $3 \mathrm{GPP}$ meetings $[9,10]$. Some of the possible use case scenarios for switching on and off cells in the network have been described as follows:

- Where there are two cells operating on different frequency bands which cover 
the same geographical area, one of the cells could be deactivated during times of light traffic.

- In a hierarchical cell structure where a macro-cell is deployed to provide continuous coverage to a large area and femto-cells are deployed to increase the capacity of specific sub-areas, the femto cells can be switched off when no traffic is detected.

- In areas where the coverage area of an LTE cell is completely overlapped by a legacy cell (e.g., UMTS or GSM), the LTE cell could be de-activated when there is no demand for high-speed data.

Although implementation details are not discussed at these meetings, the above simple scenarios would be relatively easy to implement. There are, however, some practical issues with the first and third scenarios, since there are many subscribers with older devices which may not support all frequency bands or which may be operating on the legacy network.

There is also some work presented in academic literature which discusses other use case scenarios for cell switch-off. For example, one study proposes a scheme where mobile operators offering service in the same area can save energy by switching off BSs and allowing customers to roam on each other's networks [11]. Coordination between competing operators would surely offer greater potential for energy savings, but it is difficult to determine what type of arrangement would be acceptable or feasible both from a business perspective and also from a technical perspective, since different network operators often hold licenses for different bands and may even operate on different network technologies. 
The energy savings made possible by some of the above techniques which are more limited in scope would not be as significant as a more flexible scheme which adapts to user traffic and allows some BSs to switch off while allowing the remaining BSs to expand their coverage regions. The following subsections describe the various layers and aspects which must be considered when developing a scheme for the deployment and management of a green wireless network which supports cell switch-off.

\subsubsection{Network Planning}

Effective network planning can contribute to the energy efficiency of a network if either the cell sites are chosen in a way which makes it easier to switch off cells while allowing neighbouring cells to compensate for the reduced coverage, or if coverage extension technologies such as relays are strategically deployed. One study discusses various patterns in which cells can be deployed and shows that some layouts make it easier to switch off cells when compared to other layouts [12]. The authors also argue that it is more energy-efficient to deploy a network with a greater amount of small cells where switching off a single cell has less of an impact when compared to switching off a cell in a network which has a smaller number of large cells.

\subsubsection{BS Configuration in Heterogeneous Networks}

When energy consumption at all BSs is equal, the objective in order to maximize the energy savings would be to maximize the number of cells to be switched off. However, in heterogeneous networks (HetNets), it is typical for cells to differ dramatically with respect to the size of the coverage region they are designed to serve, and therefore the amount of energy which they consume. A cell switch-off scheme for HetNets would need to distinguish between different types of cells such as 
macrocells, microcells, picocells, and femtocells, and accurately be able to model the energy consumption of these different types of cells in order to effectively maximize the aggregate energy savings in the network. Detailed energy consumption models for macrocells and microcells can be found in [13]. Another aspect of HetNets which differs from traditional networks is the use of multi-hop relaying. While relays are useful for improving cell-edge performance, and could therefore improve coverage when some cells are switched off, it would also need to be investigated how much energy a relay consumes and when, if at all, it is advantageous to switch them off.

\subsubsection{UT Assignment}

Optimizing UT-to-BS assignment through load-balancing techniques, even without modifying the transmit power of the BSs, can have a dramatic effect on quality of service [14]. Effectively load balancing UTs between the active BSs and taking advantage of technologies such as Coordinated Multipoint Transmission and Reception (CoMP) can help to offset any potential loss in coverage or quality of service during periods where some BSs are powered down.

\subsubsection{Cell Parameter Optimization}

Cell parameters such as transmit power, hand-off thresholds, and antenna tilt can be configured to guarantee coverage in areas where neighbouring cells are switched off. Antenna tilting limits the range of a cell by restricting the radiated power to a smaller geographic region, and is therefore used to minimize interference to neighbouring cells. While this is advantageous in a fully-utilized network, it impairs the ability of cells to serve UTs which fall in the coverage area of neighbouring cells that are switched off. Mechanical solutions to adaptively change the antenna tilt of 
a cell may be undesirable due to reliability concerns, but "virtual" antenna tilting is feasible through the use of remote electrical tilt (RET), which is an electrical beam tilting mechanism [15].

\subsubsection{Interference Management}

Since modern cellular networks are heavily interference-limited, cell switch-off schemes would benefit from taking into account the effects of interference when selecting which cells to switch off. Continued research in the area of inter-cell interference co-ordination (ICIC) shows that carefully assigning the bandwidth resources and limiting frequency re-use in some scenarios can improve overall network throughput [16]. Some cells may be stronger interferers than others due to high transmit power, antenna height, or close proximity to loaded neighbouring cells. Switching them off or strategically restricting the bandwidth made available to them can significantly increase the spectral efficiency of UTs in other parts of the network. This, in turn, could allow more cells to be switched off since the high spectral efficiency would allow the remaining cells to serve a greater number of UTs. In fact, some researchers are considering dynamic spectrum reduction as another technique to save energy [17]. This technique could therefore be used both to save energy and to reduce interference, and could be done jointly with cell switch-off.

\subsubsection{Time Scale}

Cell switch-off can be done using both short-term and long-term approaches. The following strategies describe a short-term cell switch-off approach, which can be used independently by each cell, and a long-term approach which must be co-ordinated at the network level [17]: 


\subsubsection{Short-term approach}

The short-term approach, called micro-sleep, entails buffering frames and scheduling them such that there are time slices where the cell is fully loaded followed by time slices where the cell is non-loaded. This occurs on the scale of milliseconds and allows the signal processing units to spend more time in sleep mode and the power amplifiers to operate at peak efficiency, which is typically at close to full load. The disadvantage of this approach is that beyond- $4 \mathrm{G}$ networks are expected to provide service for hard real-time machine-to-machine communication applications which are delay-sensitive (e.g., vehicle-to-vehicle communication). Therefore, the maximum time during which a cell can be allowed to micro-sleep would be bounded by the delay requirements for these applications, which may be in the order of 20 milliseconds [17].

\subsubsection{Long-term approach}

The long-term approach entails periodically re-configuring the base stations in the network by switching them on or off. This could occur on the scale of minutes or even hours, and would allow more significant energy savings than the short-term approach by allowing more BS components to be shut off. Typically, when longterm approaches are discussed, it is assumed that some BSs will be shut off and that its users will be handed off to neighbouring BSs. However, as research in this field progresses and the development of radio access technology moves more towards energy efficiency, it may eventually be possible for this long-term approach to be incorporated at an even shorter scale of several sub-frames so that it may be done jointly with other co-ordinated techniques such as CoMP or ICIC. 


\subsubsection{User Traffic Prediction and Modeling}

Another technique which would be useful for performing cell switch-off is UT traffic prediction. Being able to predict UT traffic is advantageous since it can allow the cell switch-off scheme to consider not only the current traffic trends in the network but how they may change until the time arrives to re-configure the network. Since it is not practical to expect that cells can be repeatedly switched on or off within short time windows, it is useful to be able to make accurate predictions of UT traffic. Some early work in this area has been done in this [18].

\subsection{Tools for Developing Cell Switch-Off Schemes}

In the following sub-sections, we discuss three possible strategies that can be used to develop cell switch-off schemes, namely by following an analytical approach, or by constructing a problem-specific heuristic, or by using general-purpose techniques which have been well studied in the field of artificial intelligence.

\subsubsection{Analytical Aspects}

It is a big challenge to design a comprehensive scheme that captures all of the configurable aspects of a cellular network by following the analytical approach of formulating closed-form mathematical expressions and solving optimization problems to minimize the energy consumption. In fact, it is likely that most schemes which are eventually used in practice will be based on computationally efficient heuristics or which yield reasonably good quality results in real-world conditions. Nevertheless, analytical work may prove useful in determining the potential for energy savings and for calculating bounds to evaluate the performance of sub-optimal schemes. The 
work presented in [19] and [20] use analytical methods to characterize the amount of energy that can be saved by reducing the number of active BSs during periods of low traffic.

\subsubsection{Problem-Specific Heuristics}

When it is too difficult, computationally too expensive, or even impossible to analytically obtain the optimal solution to a problem, the most popular alternative is to develop a heuristic which is specifically tailored to the problem. Computationally efficient heuristics can be designed to obtain very good sub-optimal solutions for many problems. However, one of the most common pitfalls with some heuristics is that they may perform very well in the problem setting which it was designed for, but may perform poorly under special circumstances which were not anticipated by the designer [21]. Another design challenge is to determine how well the heuristic performs when it has incomplete knowledge of the environment. As a result, problemspecific heuristics are ideal for many types of problems where all the possible test conditions can be easily be taken into account in the design process.

\subsubsection{Artificial Intelligence}

Artificial Intelligence (AI) techniques which can help in learning and decisionmaking are useful for problem domains where the environment and objectives are too complex to be fully characterized by closed-form mathematical expressions, such as in cognitive radio [22]. The study in [23] presents a survey of a wide variety of research in wireless which takes advantage of AI techniques such as artificial neural networks, fuzzy logic, and biologically-inspired search algorithms such as genetic algorithms (GAs), ant-colony optimization, and simulated annealing. Machine learning 
is another aspect of $\mathrm{AI}$ which allows the system to adapt to changing environments based on accumulated experience. An interesting study which takes advantage of machine learning can be found in [24], where an aggregate interference control scheme is developed for the IEEE 802.22 Wireless Regional Area Network (WRAN) standard.

We later show that the cell switch-off problem becomes very difficult to solve when a greater number of parameters are taken into account in the problem formulation. This necessitates the use of a search heuristic to solve the problem with reasonable complexity and computation time. We chose to explore the use of GAs since it was found that the construction of the cell switch-off problem allowed us to formulate it in a way which could be readily solved with a GA. Moreover, GAs have been shown to offer impressive performance in a wide variety of problem domains, and this gave us confidence that it would offer robust performance for our problem as well [25].

\subsection{Overview of Genetic Algorithms}

GAs belong to a larger class of algorithms studied in evolutionary computation (a field of artificial intelligence) which use mechanisms that are inspired by aspects of genetic evolution such as mutation, chromosomal crossover, and natural selection [26]. GAs come in many different variations, and can be applied to both single-objective and multi-objective problems [27]. In fact, there are even mechanisms which allow for GAs to be executed in a distributed manner [28]. However, all GAs share the same general approach of performing a heuristic search of a solution space with the goal of finding the optimal solution using the aforementioned evolutionary techniques. In order to apply a GA to a problem, the following two requirements must be met:

i. It must be possible to encode any solution from the solution domain as a string 


$$
\text { of "alleles", called a "chromosome". }
$$

ii. The quality of any solution, based on the objective of the optimization problem, should be quantifiable by using a "fitness function".

There are a number of key principles which should be followed when designing the fitness function and the chromosome representation for a problem [26]. For example, the chromosome representation should be as concise as possible and should lend well to mixing and matching alleles for generating new, higher quality solutions. Also, a fitness function should be computationally efficient, since it will be used many times throughout the optimization process and will therefore have a high influence on the total computation time. The procedure for a basic GA, known as the steady-state GA, is as follows [29]:

1. Generate an initial population of chromosomes either randomly or by using a heuristic which can find some good sub-optimal solutions.

2. Assign each chromosome a fitness value.

3. Select two chromosomes, either randomly or probabilistically based on their fitness values - these will be the parent chromosomes.

4. Perform a genetic crossover, which is a mechanism for exchanging alleles between the two parent chromosomes, to generate two child chromosomes.

5. Assign a fitness value to the two child chromosomes and insert them into the population by displacing two of the existing chromosomes - again, chosen either randomly or probabilistically based on their fitness values. 
6. Return to Step 3, unless either the maximum number of iterations has been reached or the population has converged to a solution.

7. Select the chromosome with the highest fitness value as the optimal solution.

In the subsections that follow, we will discuss the various aspects and components of a GA as described above. A more detailed discussion of these various elements can be found in Chapter 2 of [30].

\subsubsection{Initial Population}

The two major considerations when generating the initial population are (1) the number of individual chromosomes to generate, and (2) the mechanism through which the individuals are generated. There is no particular rule for selecting the population size, but the general consensus is that larger chromosome lengths require larger populations. Studies cited by [30] suggest a linear dependence between population size and chromosome length, and it is also indicated that in many cases good results

can be obtained with population sizes as small as 30. An approach suggested in [31] is to choose the population size as a multiple of the chromosome length.

Regarding the mechanism through which the initial population is generated, the general approach is to randomly generate the chromosomes. However, since randomly generated chromosomes do not always uniformly cover the entire search space, more "intelligent" techniques can sometimes be used in order to ensure that the entire search space is reachable from the initial population through crossover. There is also the possibility of inserting known good solutions (perhaps obtained through a simple heuristic) into the initial population. This can sometimes help the GA find better solutions more quickly, but it can also have the drawback of leading to premature 
convergence to a poor solution or a local optimum.

\subsubsection{Chromosome Selection}

The chromosome selection problem is that of selecting which chromosomes will reproduce through crossover and which chromosomes will be removed from the population. Since the goal of the GA is to find a solution which maximizes or minimizes a given fitness function, it follows that the selection procedure should somehow relate to fitness. However, always selecting the best solutions in the population for crossover can have the undesirable effect of premature convergence to a local optimum. Moreover, while some solutions may have a low fitness value, they may contain useful "genes" which can be used to improve other solutions in the population. For these reasons, chromosome selection typically follows a stochastic approach. The most widespread selection mechanisms are known as Roulette Wheel Selection (RWS) and Tournament Selection (TS). RWS constructs a probability distribution where each chromosome is assigned a selection probability which is directly proportional to its fitness. The RWS technique in its unmodified form can perform poorly under many circumstances, and often requires some level of tweaking. Some possible techniques include scaling the fitness values or constructing the probability distribution based on rank rather than absolute fitness values. TS, on the other hand, randomly selects with uniform probability a group of chromosomes from the population which then "compete" against each other to select, either stochastically or deterministically based on fitness, which two chromosomes will be used to generate the two new child chromosomes through crossover. TS has the interesting computational advantage that it does not necessarily need to know the exact fitness values of the chromosomes. In many cases, it may be enough for it to only carry out a partial evaluation 
of the fitness function in order to determine which chromosomes in the tournament group are the most fit.

The remaining issue regarding chromosome selection is the mechanism through which the new child chromosomes are inserted into the population. There are two general approaches, which are known as generational and steady-state strategies. GAs in their original form used a generational strategy, where crossover and mutation were applied to a population of $N$ chromosomes to generate a new generation of $N$ chromosomes. A concept called population overlap was later introduced as a modification to this strategy, which worked by only replacing a fixed fraction of the population at each generation. The steady-state approach takes this concept further and inserts the child chromosomes directly into the current population. It has been shown that the generational and steady-state approaches behave similarly over the long-run, but the steady-state approach can often reach better solutions in less time than the generational approach, since it allows high-fitness offspring to propagate more quickly throughout the population [32].

\subsubsection{Crossover}

The crossover operator in a GA is the mechanism which takes two parent chromosomes and recombines them to produce two child chromosomes. Crossover allows the GA to explore the search space and gradually improve the fitness of the population. A simple crossover technique, called the one-point crossover, is illustrated in Figure 2.3.1. Different crossover techniques may be more suitable for certain types of problems; we will discuss this issue in Section 3.4 when we design our GA. 


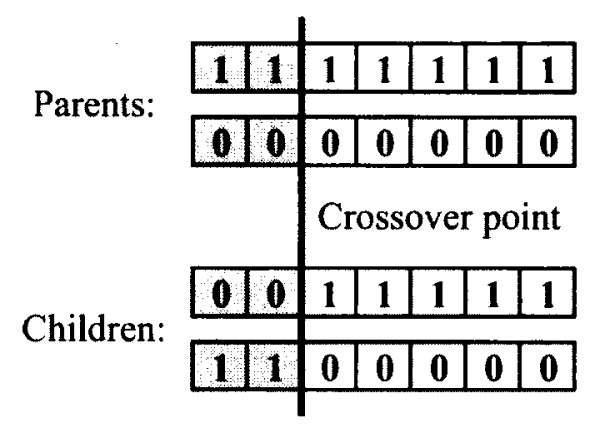

Figure 2.3.1: One-point crossover.

\subsubsection{Mutation}

The mutation operator is designed to maintain diversity in the population. Mutation makes slight alterations such as flipping a binary bit at a random position in the chromosome or exchanging the positions of two alleles. Mutation only operates on a single chromosome at a time, as opposed to crossover which requires two parent chromosomes. Mutation occurs based on a user-defined probability, and helps the GA to avoid local optima by preventing the chromosomes from becoming too similar to each other.

\subsubsection{Termination}

Stochastic search methods such as GAs, and also other methods such as ACO which were previously discussed, could theoretically continue running indefinitely. However, for the GA to be useful in practice, a termination condition needs to be placed so that a solution can be obtained. The simplest way of terminating a GA is to limit the computation time, number of fitness evaluations, or number of crossovers. The advantage of these approaches is that they allow the execution time of the GA to be bounded by some deterministic amount of time. Another approach is to monitor the diversity of the population and formulate a termination condition which is based 
on some measure of convergence.

\subsection{Related Work in Cell Switch-Off Algorithms}

\subsubsection{Cell Zooming}

Niu et al. present a centralized and a distributed version of a scheme, which they name "Cell Zooming", which executes at a pre-defined interval to shut off underutilized BSs [1]. The authors show that their centralized scheme significantly outperforms their decentralized scheme. The scheme assumes that each user has a fixed minimum rate requirement, and BSs are only switched off if its users' traffic demands can be satisfied by neighbouring BSs.

\subsubsection{Centralized scheme}

Algorithm 2.1 describes the steps of the centralized cell zooming scheme, with the variables defined as follows:

- The algorithm is executed periodically at a fixed interval of $T$ minutes

- User terminal (UT) to BS associations are specified by the binary matrix $\mathbf{X}=$ $\left[x_{i j}\right]$, where $x_{i j}=1$ if UT $i$ is associated with BS $j$, or 0 otherwise

- The downlink bandwidth at $\mathrm{BS} j$ is $B_{j}$

- The minimum rate requirement of a UT $i$ is $r_{i}$

- The spectral efficiency of a UT $i$ served by BS $j$ is $\rho_{i j}$

- The bandwidth required for a BS $j$ to satisfy the rate requirement of UT $i$ is $b_{i j}$ 
- The traffic load each BS $j$ serving their respective set of users $\mathcal{M}_{j}$ is given by the vector $\mathbf{L}$, where $L_{j}=\sum_{i \in \mathcal{M}_{j}} \frac{b_{i j}}{B_{j}}$

- A protection margin $\alpha_{j} \in[0,1]$ can be defined, which reduces the aggressiveness of the algorithm by reserving a portion of the BS's bandwidth so that the idle downlink bandwidth at BS $j$ is $\tilde{B}_{j}=\left(1-\alpha_{j}\right) B_{j}$

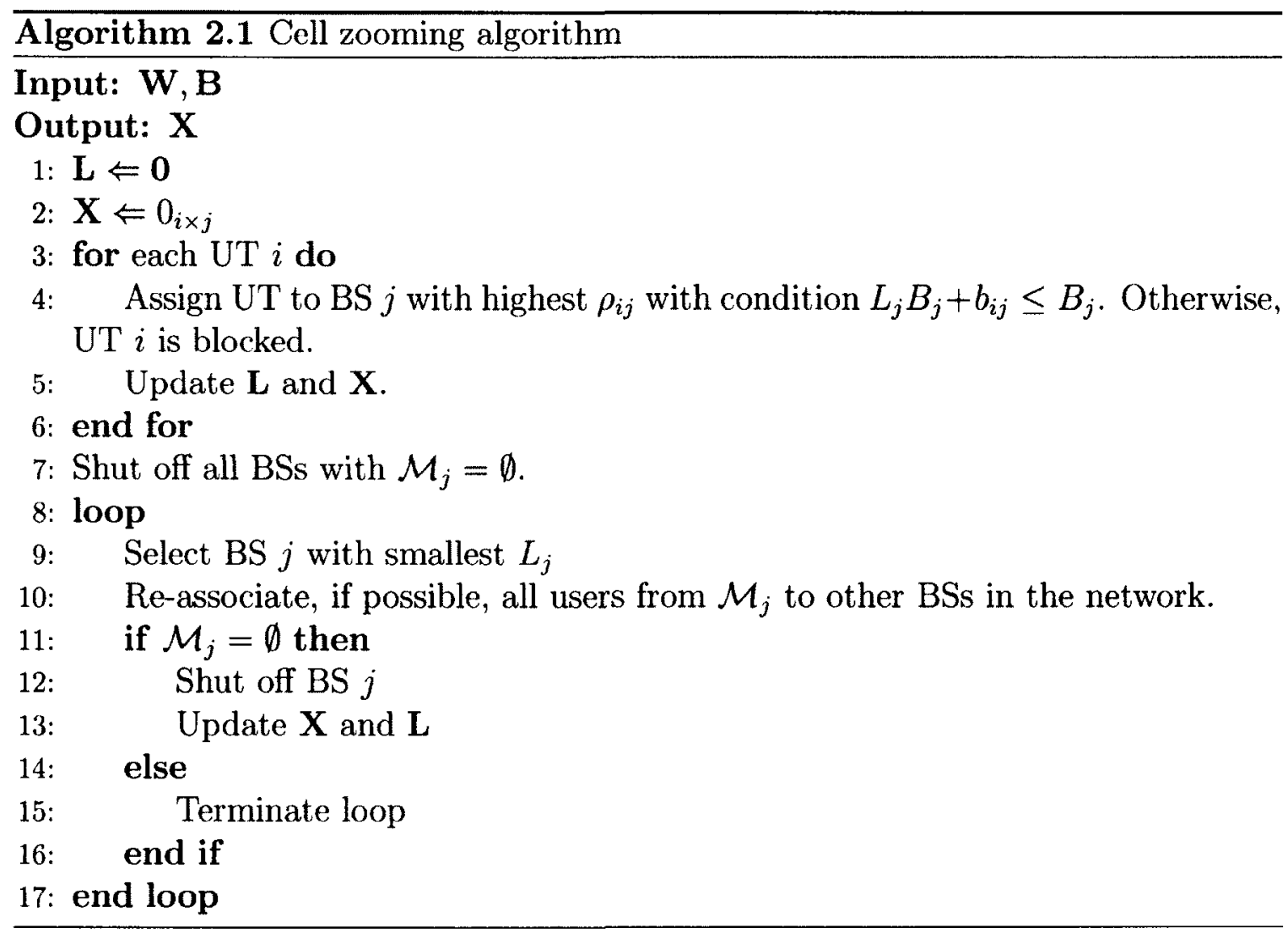

Algorithm 2.1, by design, shuts off BSs only in increasing order based on traffic load. Although it intuitively makes sense to attempt to first shut off BSs with low traffic load, following this strict ordering does not yield optimal results since the traffic load of neighbouring BSs would also be relevant to finding the optimal configuration. 
It should be noted that Algorithm 2.1 does not cause any users to go into outage at the instant the algorithm is executed. However, as time passes, there is a chance that the UT distribution could change significantly before the next time the algorithm is scheduled to be executed. This is the reason why the authors proposed that a protection margin $\alpha_{j}$ be introduced, which restricts the available bandwidth of the BSs to $\tilde{B}_{j}=\left(1-\alpha_{j}\right) B_{j}$ in the execution phase of the algorithm. This results in less BSs being shut off and leaves some spare bandwidth at each BS to decrease the blocking probability of subsequent users entering the network.

Another issue is that in order for the algorithm to be executed, all of the users must have SINR measurements from all of the nearby BSs in order to identify the BSs with which their spectral efficiency is high enough to meet their minimum rate requirement. The authors of [1] suggest that every time when the algorithm is to be executed, all of the BSs should be turned on for a short period to allow the UTs to collect the required SINR measurements. We believe that this would be undesirable for real-world applications. However, the idea of separating data from signalling in green wireless networks is already being proposed by some researchers in academia and industry [33]. As the mobile industry continues to put higher emphasis on energy efficiency, it very conceivable that future wireless network equipment will be equipped with efficient, low-power components dedicated for signalling purposes. This would allow cells to switch off data capabilities and go into a low-power sleep mode which allows signalling activity to continue.

\subsubsection{Distributed scheme}

Niu et al. also consider a distributed scheme in order to achieve lower information exchange requirements when compared to their centralized scheme. The distributed 
scheme follows a very simple approach where each UT chooses which cell to associate with based on the function defined as

$$
U\left(\rho_{i j}, L_{j}, \alpha_{j}\right)=\left\{\begin{array}{ll}
\frac{\rho_{i j}\left(L_{j} B_{j}+b i j\right)}{\dot{B}_{j}} L_{j} B_{j}+b_{i j} \leq \tilde{B}_{j} \\
0 & L_{j} B_{j}+b_{i j}>\tilde{B}_{j}
\end{array} .\right.
$$

The scheme ranks the cells in order of preference using Equation 2.4.1, which gives precedence to cells which offer high spectral efficiency but which can accommodate the UT but are already highly loaded. Since UTs are made to prefer cells which are already highly loaded, some cells are left unutilized after all the UTs have chosen which cells to associate with, and these unutilized cells are then switched off.

The results presented in [1] show that the distributed scheme produces significantly inferior results when compared to the centralized scheme. Although the low co-ordination and computational requirements of distributed algorithms are a desirable trait, there is no pressing need to avoid co-ordination between cells in the context of cell switch-off since the information being exchanged is relatively small in size and is delay-insensitive. In this case, we believe that the superior results offered by the centralized algorithm outweighs the low overhead requirements of the distributed algorithm.

\subsubsection{Dynamic Base Station Energy Saving}

Zhou et al. present a scheme in [34] which they call dynamic base station energy saving. Algorithm 2.2 describes the steps followed by their scheme. $\mathcal{B}$ is defined as the set of BSs, and $\mathcal{U}$ is defined as the set of all UTs. The spectral efficiency between a UT $i$ and BS $b$ is denoted by $\rho_{b i}$ and the minimum rate requirement of each UT is defined by $r_{i}$. The energy consumed by BS $b$ and the maximum bandwidth available 
for use by a BS $b$ are defined by $W_{b}^{\max }$ and $P_{b}$, respectively. The main difference between the operation of this scheme and the one presented in [1] is that it tries to perform the UT assignment and cell switch-off jointly by assuming that each cell is switched off by default and then switching on as few cells as possible while UTs are being assigned. In contrast, the scheme in [1] assigns the UTs first with the assumption that all of the cells are switched on, and then attempts to switch off as many as possible. Both approaches carry benefits and drawbacks, some of which we will discuss in the following chapter.

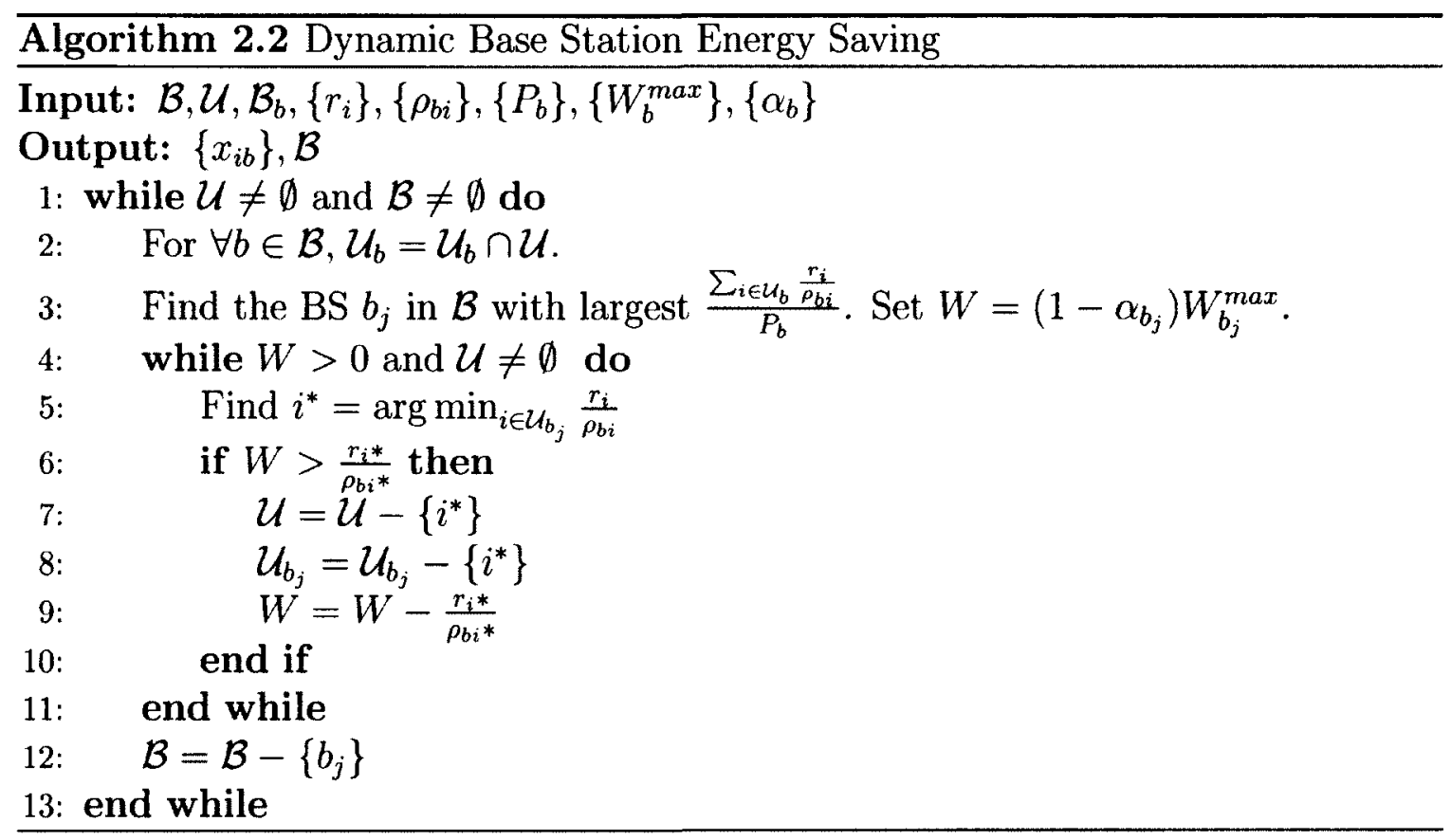




\section{Chapter 3}

\section{Proposed Cell Switch-Off Schemes}

In this chapter, we present our proposed cell switch-off schemes. We first describe our BILP formulation in Section 3.1, under the assumption that interference is constant. We then present a computationally efficient heuristic based on the "cell zooming" scheme given in [1], which we call "enhanced cell zooming" (ECZ) in Section 3.2. We then adapt the ECZ scheme to work in scenarios where interference is a function of the set of active cells in the network, which we call "interference-aware cell zooming" (IACZ) in Section 3.3. In Section 3.4 we present our GA-based algorithm, which we call "interference-aware genetic algorithm" (IAGA), along with the description of its parameters and crossover and mutation operators.

In all of our schemes which we present in this chapter, the objective is to maximize the number of cells switched off in the network. We believe that this is a good approximation of energy savings, due to studies such as [13] which show that the static portion of a cell's energy consumption is much greater than the dynamic energy consumption which depends on traffic. When we switch off a cell, we assume that all the equipment such as the baseband processing chips and power amplifiers are shut down, which make up the majority of a cell's energy consumption as was shown in Figure 1.0.1. Since these components are also responsible for generating heat, this would also allow the cooling mechanisms to switch off shortly afterwards. We assume, 
as envisioned by researchers in [33], that there will be dedicated low-power signalling equipment which would facilitate for the cell to be switched on when required at a later time. It was suggested in [1] that the cell switch-off algorithm could be executed at fixed intervals to decide which cells to switch off (or to switch on). We believe that a more effective approach would be to monitor the traffic and outage levels across all the cells in the network. A high traffic load or outage level would indicate that it is an appropriate time to re-execute the algorithm to allow some more cells to be switched on. Similarly, a low traffic load would indicate that the algorithm should be re-executed to allow some cells to be switched off.

\subsection{Binary Integer Linear Programming Formulation}

We begin by defining the variables and parameters which we need in order to formulate the problem as a BILP problem:

- $x_{i, j}$ : binary variable such that $x_{i, j}=1$ if user $i$ is connected to sector ${ }^{1} j$

- $y_{j}$ : binary variable such that $y_{j}=1$ if sector $j$ is active

- $\rho_{i, j}$ : spectral efficiency for user $i$ if it is associated to sector $j$

- $B_{j}:$ total bandwidth for sector $j$

- $R_{i}$ : minimum rate requirement for user $i$

- I: number of users

- $J$ : number of sectors

${ }^{1}$ In $4 \mathrm{G}$ terminology, each sector is in fact a cell. We use the term "sector" here to re-inforce that each of the cells located at a particular site can be switched off independently from the rest. 
We first consider the assumption where the spectral efficiencies $\rho_{i, j}$ are independent from the binary variables $y_{j}$ and $x_{i, j}$. As a result, the interference power must be fixed as a constant for all users. Two possible ways of doing this are by assuming either (a) the best-case scenario, which occurs when interference power is zero (i.e., SINR equals SNR for all users); or (b) the worst-case scenario, which occurs when all resource blocks are used at all the cells. We observe that assumption (a) yields the upper-bound and assumption (b) yields the lower-bound for the number of cells which can be switched off, since (a) over-estimates and (b) under-estimates the spectral efficiencies of the UTs. The authors of [1] followed assumption (a). However, it should be noted that (a) is an unachievable bound, since it is physically impossible for there to be no interference in the network; even if inter-cell interference coordination is used, it is at the expense of bandwidth and it still can not completely eliminate interference. On the other hand, (b) yields an achievable bound since it is the worst-case scenario. Following either assumption, the problem can be formulated as a BILP problem as follows:

$$
\begin{array}{ll}
\underset{x_{i, j}, y_{j}, \forall i, j}{\operatorname{minimize}} & \sum_{j=1}^{J} y_{j} \\
\text { subject to } & \sum_{i=1}^{I} x_{i, j} \frac{R_{i}}{\rho_{i, j}} \leq B_{j}, \quad \forall j \\
& x_{i, j} \leq y_{j}, \quad \forall i, j \\
& \sum_{j=1}^{J} x_{i, j}=1, \quad \forall i \\
& x_{i, j}, y_{j} \in\{0,1\}, \quad \forall i, j
\end{array}
$$

It should be noted that integer programming problems (IP) are NP-hard. The satisfiability problem for BILP, a special case of IP, was one of the 21 problems shown 
to be NP-complete by Karp in his landmark paper in computational complexity theory [35]. Nevertheless, the problem can be solved efficiently for a relatively small number of users and can therefore serve as a benchmark for other heuristics. However, defining the spectral efficiencies $\rho_{i, j}$ as a function of the cell configuration $y_{j}$ or UT assignment $x_{i, j}$ makes the problem non-linear and hence much more difficult to solve, thereby necessitating a good heuristic.

\subsection{Enhanced Cell Zooming Heuristic}

Our heuristic, presented in Algorithm 3.1, is an improvement to the $\mathrm{CZ}$ algorithm given in [1], which we described in Algorithm 2.1. The $\mathrm{CZ}$ algorithm tries to switch off the cell with the lowest utilization, and it terminates if it is not able to do so, even if there are other cells which could potentially be switched off instead. Algorithm 3.1, which we call enhanced cell zooming (ECZ), also tries to switch off cells with low utilization, but it does not terminate until it has attempted to switch off each individual cell in the network. Although the changes which we made to Algorithm 2.1 were relatively small, we see that they yield substantial improvements in the results. This is because utilization can not be treated as the exclusive factor which determines how easily a cell can be switched off. Other important factors include the utilization at neighbouring cells and the spectral efficiency between the UTs and neighbouring cells, which both determine how easily the network can hand off the UTs from a cell and subsequently switch it off.

\subsection{Interference-Aware Cell Switch-Off Scheme}

We now proceed by considering how to design an algorithm which is interferenceaware. In other words, instead of assuming worst-case interference, which occurs 


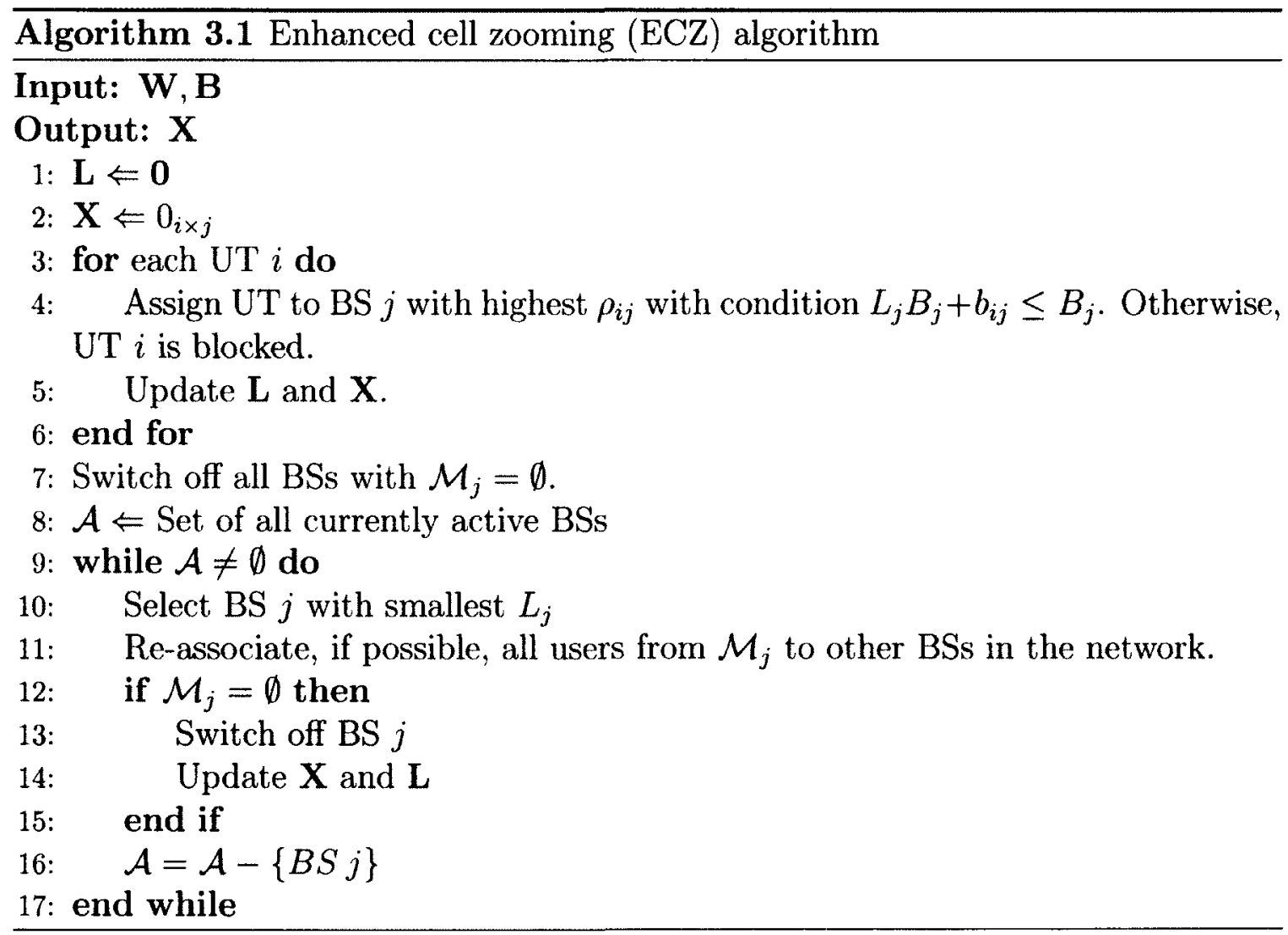

when all radio resources are being used by all cells, we only consider the interference from the cells which are active. Following the interference-aware approach allows for a more realistic modelling of the network. However, in order to maintain a reasonable level of computational complexity, the interference is still calculated based on the assumption that each active cell is using all of its radio resources. Assuming full resource utilization at the active cells provides a significant computational advantage since as a result, interference only needs to be calculated when a cell is switched on or off as opposed to each time a UT is assigned to a cell. This is also a more reasonable worst-case bound, since switching off cells will cause the utilization levels at the remaining cells to increase due to the extra bandwidth needed to satisfy UTs absorbed from neighbouring cells. 
As we discussed in Sections 2.4.1 and 2.4.2, an iterative solution for the cell switch-off problem can be built either by initializing all cells to be switched on and then incrementally switching them off, or by initializing all cells to be switched off and then incrementally switch them on. These two approaches are comparable in the constant-interference case. However, in the interference-aware case, the second approach is more problematic, since the interference introduced by switching on a cell can cause a highly loaded nearby cell to become overloaded. This does not occur when the first approach is used, which is why we continued to build upon Algorithm 3.1 to develop our interference-aware algorithm, which we present in Algorithm 3.2.

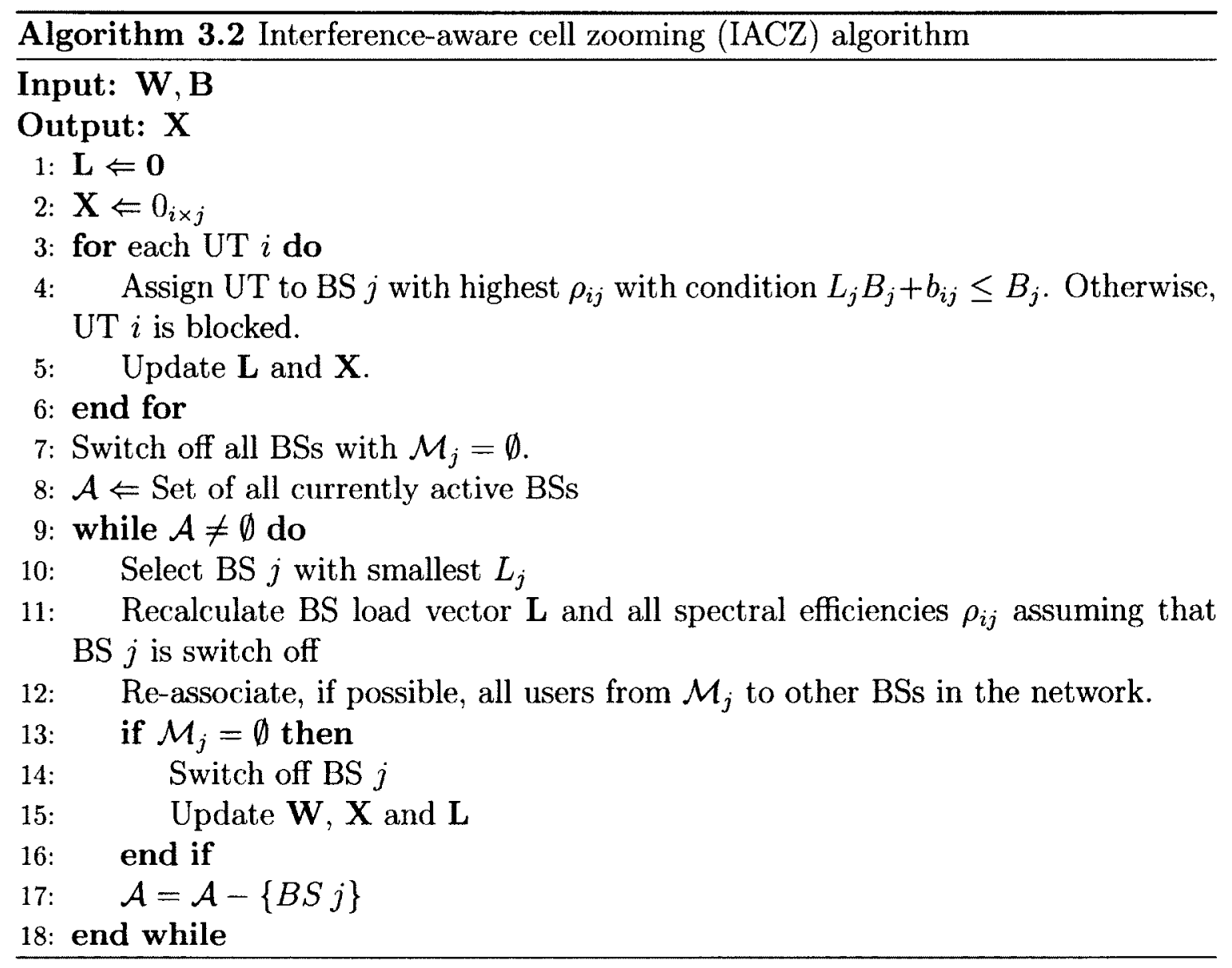




\subsection{Genetic Algorithm Based Interference-Aware Cell Switch-Off Scheme}

Using an iterative approach to solve a problem as we have done is a widely used technique for solving problems that are otherwise too complex to be solved mathematically in a single step. However, the performance of iterative algorithms must be carefully evaluated since they do not necessarily produce optimal results. The solution generated by an iterative algorithm inherently depends on the quality of the decision-making at each iteration. In the case of a cell switch-off algorithm, making a poor decision on which cell to switch off at any given iteration reduces the quality of the final result. This is especially the case in an interference-aware algorithm, since each cell produces a different amount of interference to the UTs in the network. We have already shown that while aiming to switch off cells with low utilization can be used as a reasonable guideline, strictly following this approach yields poor results. While we were able to solve the constant-interference case as an optimization problem and compare the results with Algorithm 2.1, the high complexity in the interferenceaware case did not allow us to do the same for Algorithm 3.2. Instead, we designed a GA in order to search for the best ordering in which to iteratively switch off the cells and bring our results from Algorithm 3.2 closer to optimality. The following sub-sections describe how each of the GA's components, as listed in Section 2.3, were designed.

\subsubsection{Chromosome Representation and Fitness Function}

The chromosome representation which we chose for the problem is an array of numbers where each number represents a cell (denoted by $\mathcal{B}$ in Algorithm 3.3). The 
order of the numbers represents the order in which the algorithm will attempt to switch off the cells.

The fitness value of each chromosome is the number of cells that are successfully turned off using this ordering, less the average cell load in the network. This way, if there are two different solutions which both succeed in switching off the same number of cells, the solution which results in a lower average load will be favoured since this is indicative of a more spectrally efficient UT assignment. The fitness function uses Algorithm 3.3 to calculate how many cells can be switched off given a chromosome $\mathcal{B}$.

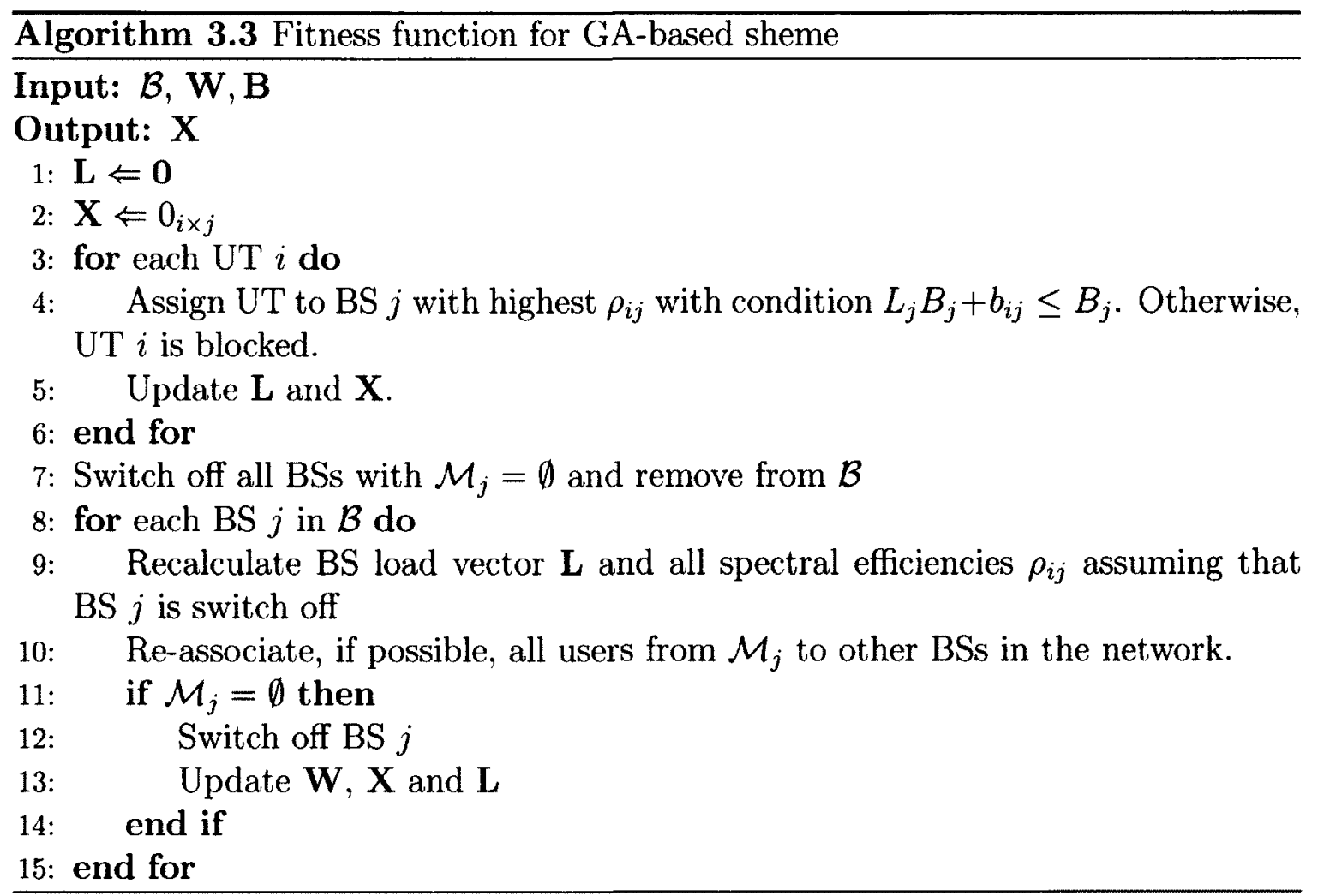




\subsubsection{Crossover Operators}

Designing or choosing an appropriate crossover operator can often have a major impact on the success of a genetic algorithm. The performance of a crossover operator may vary significantly across different problem domains, and may even be incompatible with some types of problems. For example, our problem is an ordering problem where each gene must appear exactly once in the chromosome. Consequently, the one-point crossover operator discussed in Chapter 2 can not be used since it would not preserve the validity of the chromosomes (i.e., some genes may be duplicated and others may be removed). However, there are other crossover operators which were designed to solve problems which require ordered chromosomes such as the well-known travelling salesman problem (TSP). These crossover operators are often referred to as ordered crossover. Among the most widely used ordered crossover operators are the partially matched crossover (PMX) and the order crossover (OX) [36]. We implemented both of these crossover operators, and describe their operation in the subsections that follow.

\subsubsection{Partially matched crossover}

Partially matched crossover is implemented by randomly picking two positions which form a matching section between the two parent chromosomes. Each of the two child chromosomes are generated by copying the alleles which fall within the matching section from one parent into the other parent, while moving the displaced alleles into other positions in a way which preserves the validity of the child chromosome. An example of how this is done can be seen in Figure 3.4.1. 

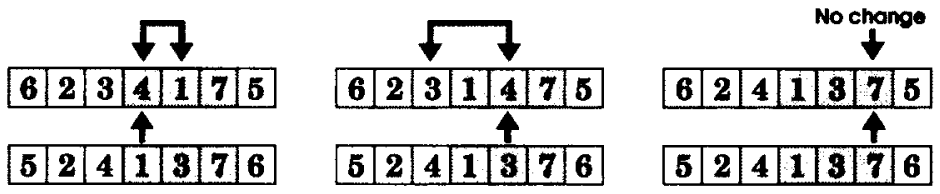

First offspring: \begin{tabular}{|l|l|l|l|l|l|l|}
6 & 6 & 4 & 1 & 3 & 7 & 5 \\
\hline
\end{tabular}
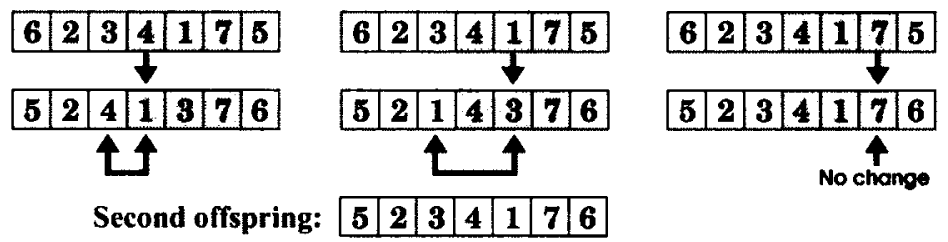

Second offspring: \begin{tabular}{|l|l|l|l|l|l|l|}
\hline 5 & 2 & 3 & 4 & 1 & 7 & 6 \\
\hline
\end{tabular}

Figure 3.4.1: Partially matched crossover (figure taken from [4]).

\subsubsection{Order crossover}

Order crossover is implemented by generating a binary mask string of the same length as the parents. The child is constructed by copying all of the alleles of the first parent which correspond to the 1 s of the mask string. The alleles which correspond to the 0 s of the mask string are then re-ordered according to how they appear in the second parent. An example of how this is done can be seen in Figure 3.4.2.

First parent \begin{tabular}{|l|l|l|l|l|l|l|l|l|l|l|l|l|}
\hline 6 & 2 & 3 & 4 & 1 & 7 & 5 \\
\hline
\end{tabular}

Mask \begin{tabular}{|l|l|l|l|l|l|l|}
\hline 1 & 0 & 1 & 0 & 1 & 0 & 1 \\
\hline
\end{tabular}

\begin{tabular}{l|l|l|l|l|l|l|l|l|l|l|l|l|l|l|} 
First offspring & 6 & 7 & 3 & 4 & 1 & 2 & 5 \\
\hline
\end{tabular}

Figure 3.4.2: Example for order crossover. 


\subsubsection{Mutation}

In ordered chromosomes, the two most popular ways to perform a mutation is to randomly select two sites and to either swap the positions of the respective genes, or to invert the order of the genes which lie between the two sites.

\subsubsection{Initial Population, Chromosome Selection, and Termination Conditions}

Although there are some general guidelines which help in GA parameter selection, there are no particular set of rules and therefore the parameters are typically chosen experimentally. For choosing the size of the initial population, we follow the approach suggested by [31], which is to choose the population size as a multiple of the chromosome length. After experimentation, we found that choosing the initial population to be equal to the chromosome length (i.e., the number of cells, which is 57 for the regular hexagonal cell layout scenario), generated good results. Increasing the initial population beyond this point did not yield any improvements. Decreasing this number, on the other hand, yielded poorer results.

For chromosome selection, we implemented tournament selection, since Roulette Wheel Selection usually requires major modifications to yield good results. When choosing the tournament group size, it was found (unsurprisingly) that choosing relatively large numbers such as 15 resulted in premature convergence to the current best solution in the population. Choosing smaller numbers such as 5 slowed down the convergence process and generated higher quality results. Termination should occur after the population converges to an optimal solution, and we found experimentally that this would occur after about 50 to 70 crossover operators. We set the termination condition of the GA to 70 crossover operations in order to be sure that the best result has been found. 


\section{Chapter 4}

\section{Simulation System Model}

Conventional system-level simulation tools for cellular networks typically operate at a very fine time scale in the order of milliseconds, which is close to the typical duration of a subframe. This is essential for evaluating the performance of many advanced physical (PHY) and media-access control (MAC) layer technologies such as Multiple Input Multiple Output (MIMO), Coordinated Multiple Point Transmission/Reception (CoMP), and Intercell Interference Coordination (ICIC). However, wireless systems are also evolving with technologies which operate at the network level. For example, 3GPP members have been investigating self-optimizing network (SON) use cases for $4 \mathrm{G}$ networks and beyond [37]. Some use cases of SON, among many, include energy saving, load balancing between cells, handover parameter optimization, and modification of antenna tilts for coverage and capacity optimization. These type of use cases require algorithms which operate at much slower speeds when compared to PHY or MAC technologies, since the underlying variations (e.g., users entering and leaving the network, fluctuations in traffic load, or environmental changes) occur at time scales in the order of minutes, hours, or even days. Therefore, when evaluating these algorithms, it is not necessary to take into account small-scale variations such as fast fading which occur in the order of milliseconds. The authors of [38] present a mathematical framework for simulating SONs and also present various use cases and some simulation results. Since our cell switch-off scheme is designed 
to operate over a slow time scale, we use a similar simulation framework which follows the standard parameters and assumptions from the ITU-R guidelines in [2] for evaluating IMT-Advanced systems but omits scheduling and fast fading.

\subsection{Channel and Interference Model}

The power $P_{R X}(i, j)$ received by the $i$-th UT from the $j$-th cell is calculated with the expression

$$
P_{R X}(i, j)=\frac{P_{T X}(j) \cdot A(i, j)}{P L(i, j)},
$$

where $P_{T X}(j)$ is the transmit power of the $j$-th cell, $P L(i, j)$ is the large-scale attenuation caused by shadowing and distance-dependent pathloss between the $i$-th UT and $j$-th cell, and $A(i, j)$ is the antenna pattern gain based on the directionality of the antenna. The formulae for $P L(i, j)$ and $A(i, j)$ are given below:

$$
P L(i, j)[\mathrm{dB}]=36.7 \log _{10}\left(d_{i j}\right)+22.7+26 \log _{10}\left(f_{c}\right)+X_{\sigma},
$$

where $d_{i j}$ is the distance (in meters) between the $i$-th UT and $j$-th cell, $f_{c}$ is the carrier frequency (in $\mathrm{GHz}$ ), and $X_{\sigma}$ is a Gaussian random variable with a mean of $0 \mathrm{~dB}$ and standard deviation of $\sigma \mathrm{dB}$;

$$
A(i, j)[\mathrm{dB}]=-\min \left[-\left(A\left(\theta_{i j}\right)+A\left(\phi_{i j}\right)\right), 20 \mathrm{~dB}\right],
$$

where $A\left(\theta_{i j}\right)$ is calculated as

$$
A\left(\theta_{i j}\right)[\mathrm{dB}]=-\min \left[12\left(\frac{\theta_{i j}}{70^{\circ}}\right)^{2}, 20 \mathrm{~dB}\right]
$$

and $A\left(\phi_{i j}\right)$ is calculated as

$$
A\left(\phi_{i j}\right)[\mathrm{dB}]=-\min \left[12\left(\frac{\phi_{i j}-\phi_{t i l t}}{15^{\circ}}\right)^{2}, 20 \mathrm{~dB}\right] .
$$


As mentioned above, we do not consider small-scale fading, since it averages out over the longer time scale in which our scheme operates. The SINR between the $i$-th user and $j$-th cell can then be calculated by the expression

$$
\operatorname{SINR}(i, j)=\frac{P_{R X}(i, j)}{P_{N}+\sum_{k \neq j} P_{R X}(i, k)},
$$

where $P_{N}$ is the noise power, and $P_{R X}(i, j)$ is given by Equation 4.1.1. The bandwidth $B(i, j)$ required by the $i$-th UT to achieve a bit rate $R$ with the $j$-th cell is then calculated with the Shannon capacity formula

$$
B(i, j)=\frac{R}{\log _{2}(1+\operatorname{SINR}(i, j))} .
$$

\subsection{Simulation Scenarios}

We consider three types of scenarios, which we discuss in the sections that follow, in which to evaluate the performance of our cell switch-off schemes.

\subsubsection{Regular Hexagonal Layout}

Dense micro-cell deployments are one of the most relevant test environments for evaluating cell switch-off schemes, since there is a greater amount of underutilization which occurs during off-peak hours when compared to rural macro-cell deployments. Micro-cell environments are heavily interference-limited, which should make it relatively easy to maintain good coverage even when a large number of cells are shut off. For this scenario, we ran our simulations using 19 BSs on a regular hexagonal grid, each serving 3 cells with full frequency re-use as shown in Figure 4.2.1. Table 4.2.1 summarizes the parameters used for this scenario, which are defined in the urban micro-cell (UMi) downlink scenario from the ITU-R guidelines in [2]. 


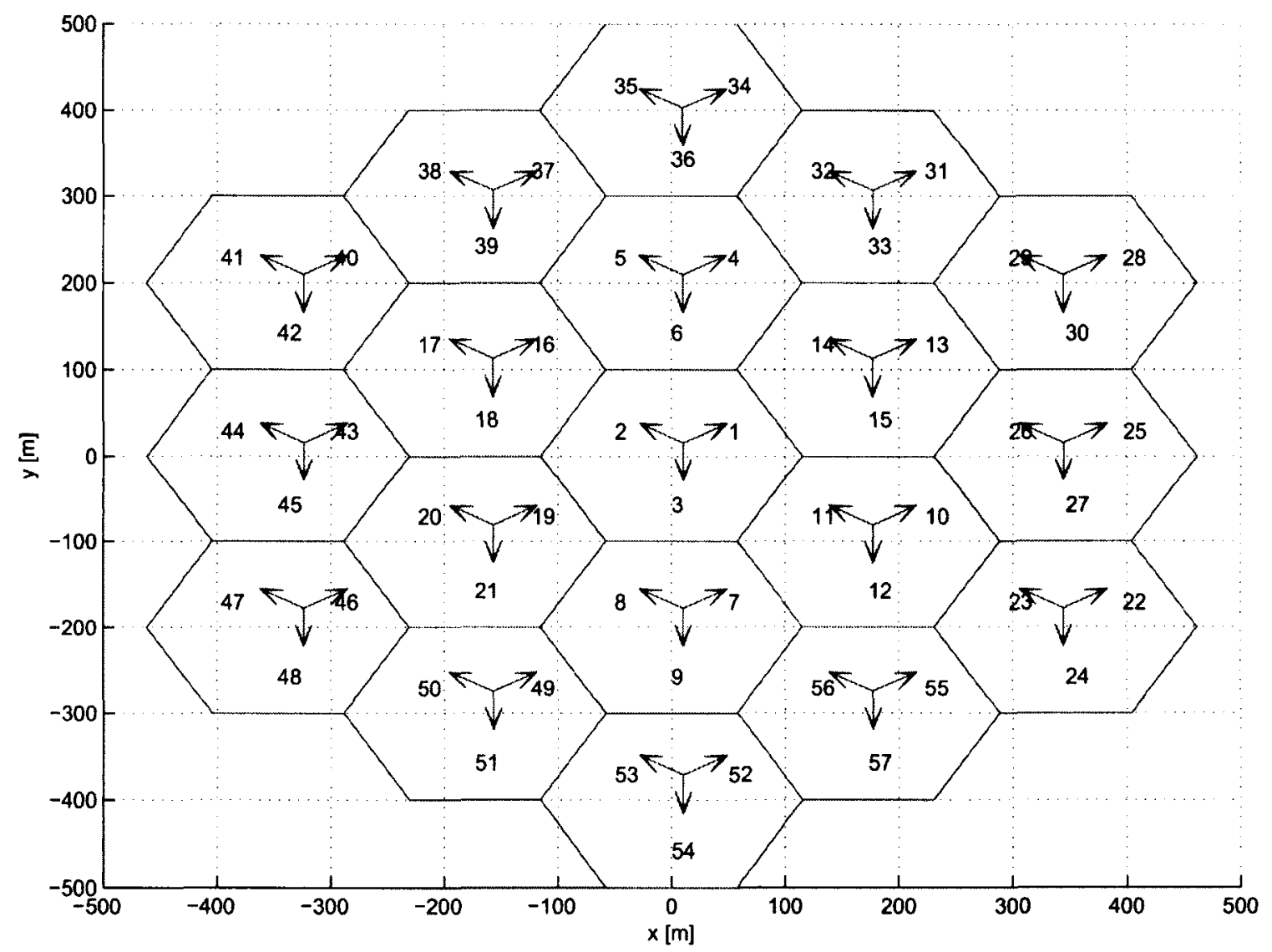

Figure 4.2.1: Regular hexagonal layout, with arrows representing cells served by 120 degree sector antennas. 


\begin{tabular}{lc}
\hline Parameter & Assumption or Value \\
\hline Cellular layout & Hexagonal grid with wrap-around \\
Number of cells & 57 (19 sites with 3 cells each) \\
Inter-site distance & $200 \mathrm{~m}$ \\
Minimum distance b/w UT and BS & $10 \mathrm{~m}$ \\
UT locations & 2D uniform probability distribution, \\
& $50 \%$ UTs indoors \& $50 \%$ UTs outdoors \\
Outdoor-to-Indoor Pathloss & $20 \mathrm{~dB}$ \\
Bandwidth (downlink) & $10 \mathrm{MHz}$ \\
Carrier frequency & $2.5 \mathrm{GHz}$ \\
Thermal noise level & $-174 \mathrm{dBm} / \mathrm{Hz}$ \\
BS antenna height & $10 \mathrm{~m}$ \\
BS antenna gain & $17 \mathrm{dBi}$ \\
UT height & $1.5 \mathrm{~m}$ \\
UT antenna gain & $0 \mathrm{dBi}$ \\
BS transmit power & $41 \mathrm{dBm}$ \\
Antenna tilt $\left(\phi_{t i l t}\right)$ & $12^{\circ}[39]$ \\
Feeder loss & $2 \mathrm{~dB}$ \\
Shadowing standard dev. $(\sigma)$ & $4 \mathrm{~dB}$ \\
\hline
\end{tabular}

Table 4.2.1: Summary of simulation parameters [2] 


\subsubsection{Regular Hexagonal Layout with Varying Energy Consumption Levels}

In real-world deployments, different BSs can consume different amounts of energy due to a variety of reasons. The most obvious reason would be that macro-cells with large coverage areas consume significantly more energy than micro-cells which cover smaller areas. There are, however, other factors as well. Recent deployments may use more modern and innovative cooling equipment which, for example, can extract cold outdoor air during the winter. Studies have also shown that the implementation of the backhaul also has a measurable impact on the total energy consumption at a BS [40]. Moreover, as transistor sizes continue to shrink in accordance with Moore's Law, processing chips continue to offer significantly better performance per Watt consumed. Research and development for higher efficiency power amplifiers is also ongoing. Some cell sites may even make use of off-grid energy sources such as solar energy. In future smart power grids, energy will even have different costs at different times of the day depending on the supply and demand in the area.

For this scenario, we use the same parameters for the UMi scenario referred to for the previous scenario, but we label each BS as either an energy-efficient or energyinefficient BS. For the sake of simplicity in implementation and in presenting the results, we assume that a randomly selected set of 9 energy-inefficient BSs consume double the energy of the remaining 10 energy-efficient BSs. Although this is a synthetic scenario, and in reality there would be a larger variety of energy consumption levels due to the aforementioned reasons, we believe that it is nonetheless an interesting scenario to examine in order to determine if varying the energy consumption can have an impact on the performance of the algorithms being evaluated. 


\subsubsection{Non-Regular Layout}

The previous scenarios are based on a regular hexagonal cell layout in accordance with the ITU-R guidelines. We now consider what happens in non-regular layouts, since real-world deployments are typically non-regular in nature, as can be seen in Figure 4.2.3, which shows the Rogers cell site locations in downtown Montreal. We consider two non-regular layouts as described in the following subsections, one of which is a synthetic scenario and the other which approximates a real-world deployment.

The SOCRATES (Self-Optimisation and self-ConfiguRATion in wirelEss networkS) research project, funded by the European Union, was recently completed by a group of leading European industry and research institutions [41]. The aim of the project was to develop and evaluate algorithms for self-configuration, selfoptimization, and self-healing for 3GPP LTE based wireless networks. One of the synthetic simulation scenarios which they considered was the Springwald layout, described in [14]. The Springwald layout is constructed by sampling 12 points on an Archimedian Spiral. In order to facilitate the simulation and wrap-around, which we discuss in the subsequent section, we replicated the Springwald layout by overlaying it on the 19-site hexagonal layout as shown in Figure 4.2.2.

\subsection{Wrap-Around}

When simulating a network, only a limited number of cells can be generated. This causes an edge effect in the outer cells, where UTs experience less interference and therefore have higher SINRs due to the fewer number of neighbouring cells. For this reason, we wrap around the cells as shown in Figure 4.3.1 in order to ensure that 


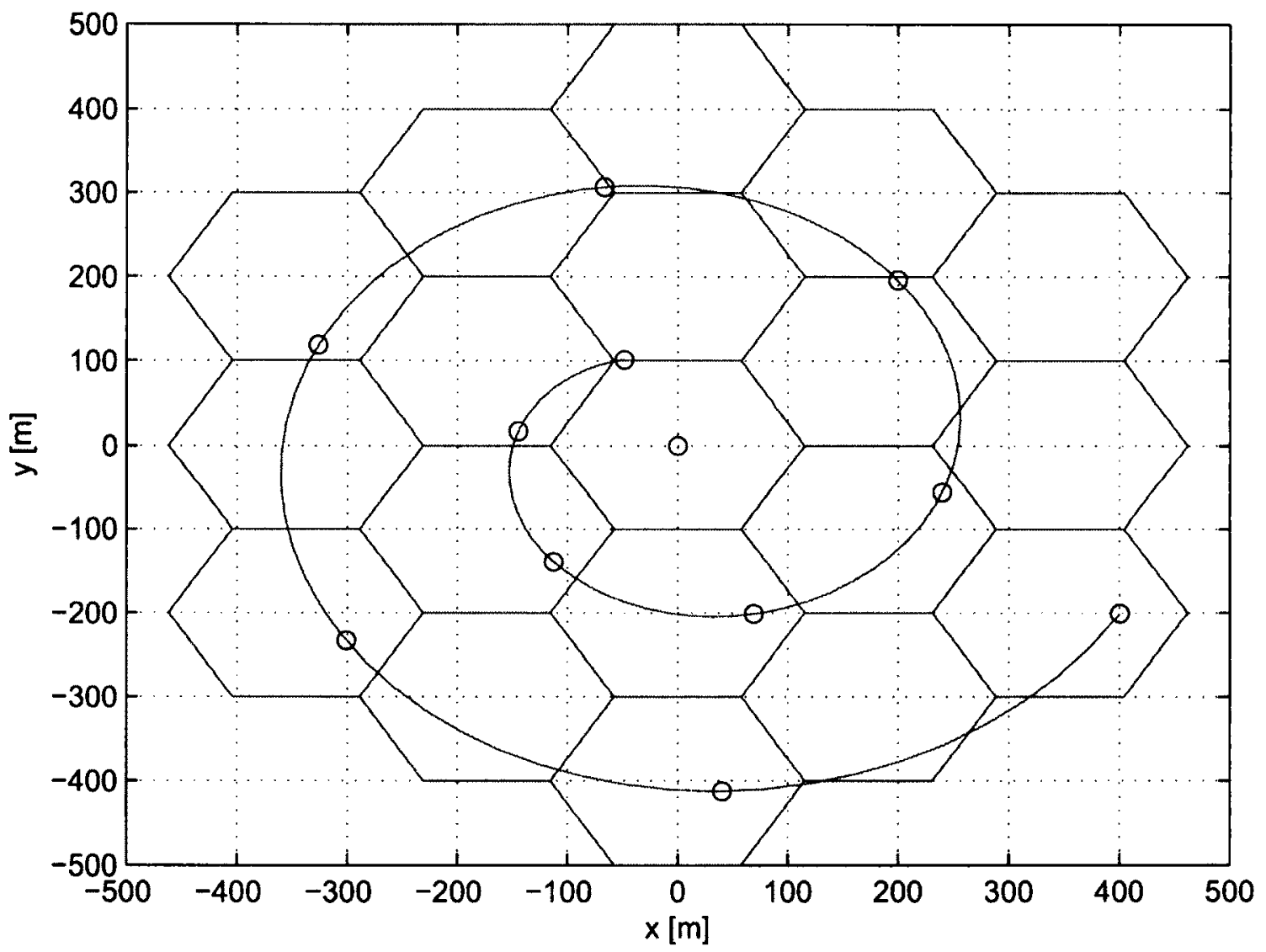

Figure 4.2.2: Springwald layout overlaid on a hexagonal grid, with black circles representing the BS locations. 


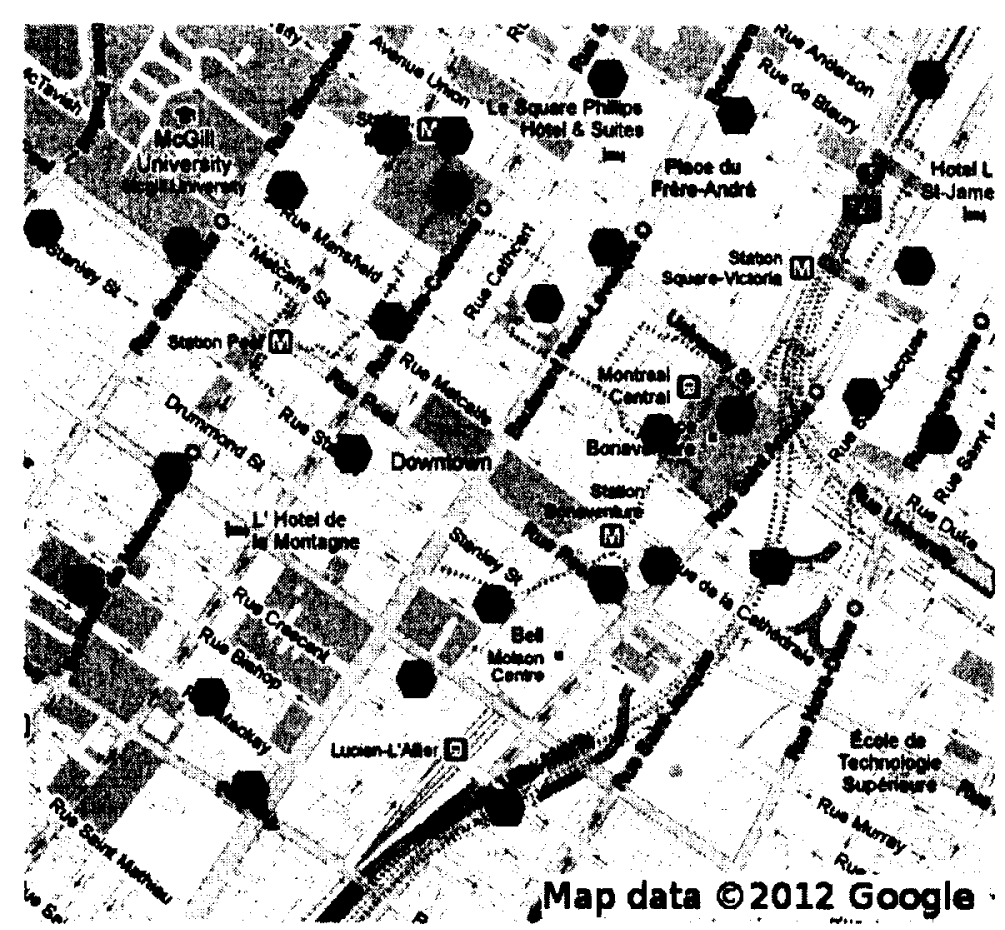

Figure 4.2.3: Rogers cell site locations in downtown Montreal, denoted by the blue hexagons (image retrieved from http://www.loxcel.com/celltower).

the SINR distributions are consistent across cells. In order to verify the accuracy of the simulator, the UT SINR distributions were compared against the WINNER+ calibration data found in [39]. Figure 4.3.3 shows the SINR distribution without wrap-around, and it can be seen that the UTs located in cells on the outer ring have a higher SINR distribution compared to the UTs located in the inner cells. Figure 4.3.3 shows the SINR distribution with wrap-around, where all cells have the same SINR distribution.

\subsection{User Distribution and Traffic Model}

We consider two types of user distributions in our simulations. Firstly, we consider a uniform distribution in which UTs have a uniform probability of appearing anywhere in the network. We also consider an overlaid hotspot distribution, where 


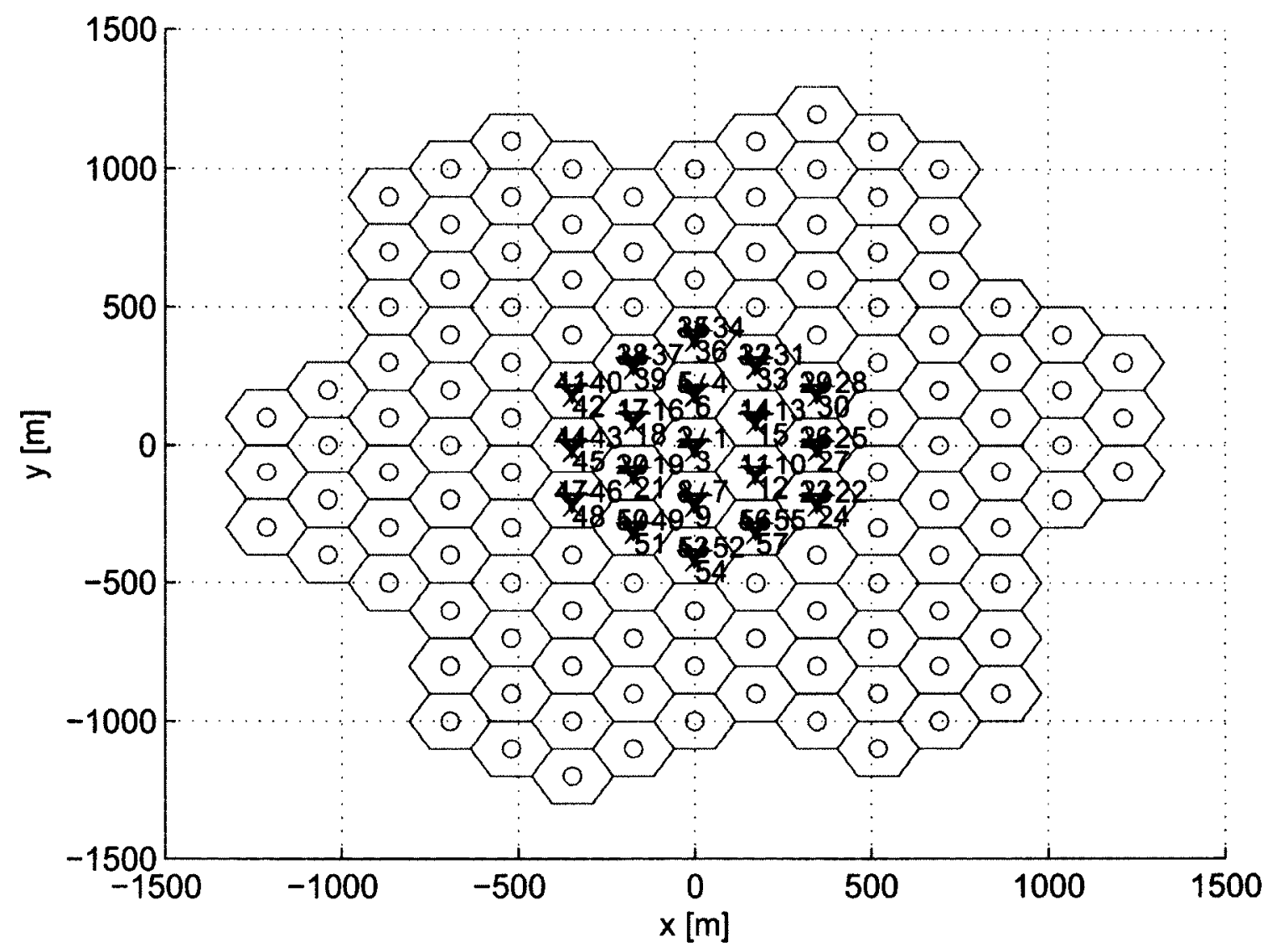

Figure 4.3.1: Regular hexagonal cell layout with wrap-around. 


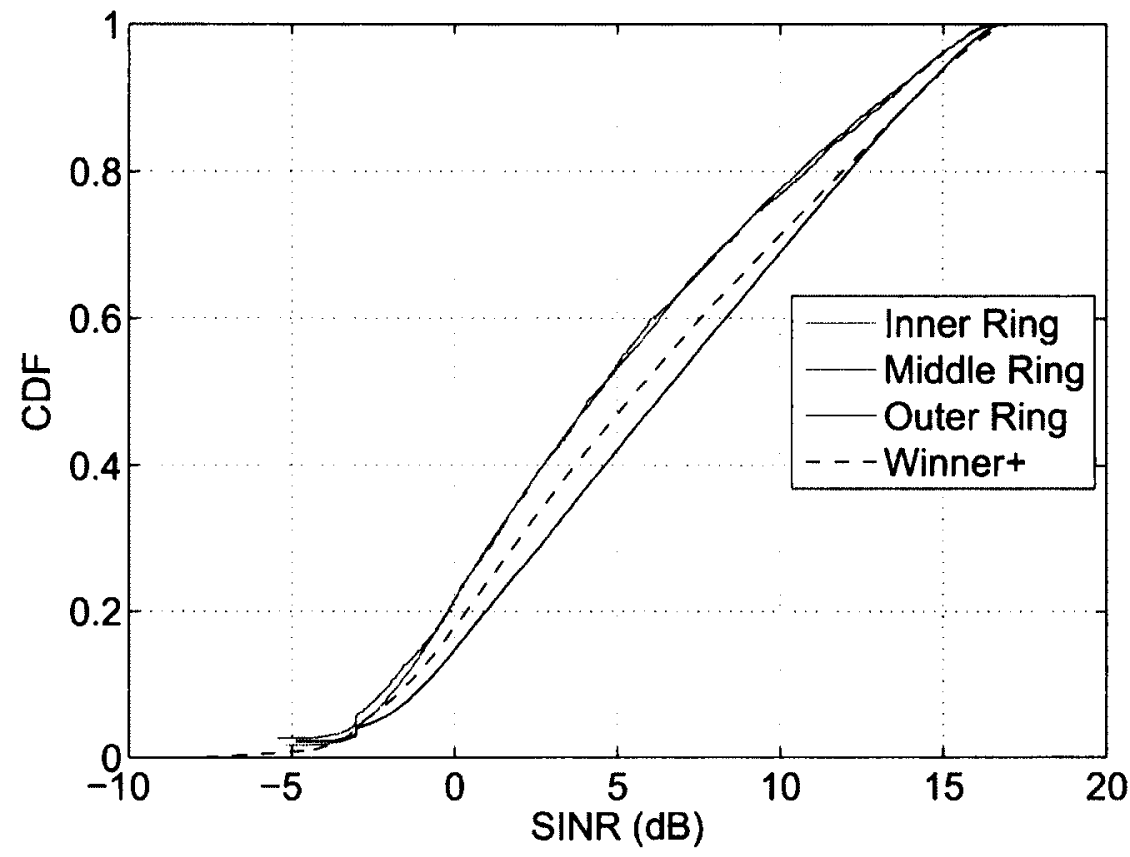

Figure 4.3.2: SINR curves without wrap-around.

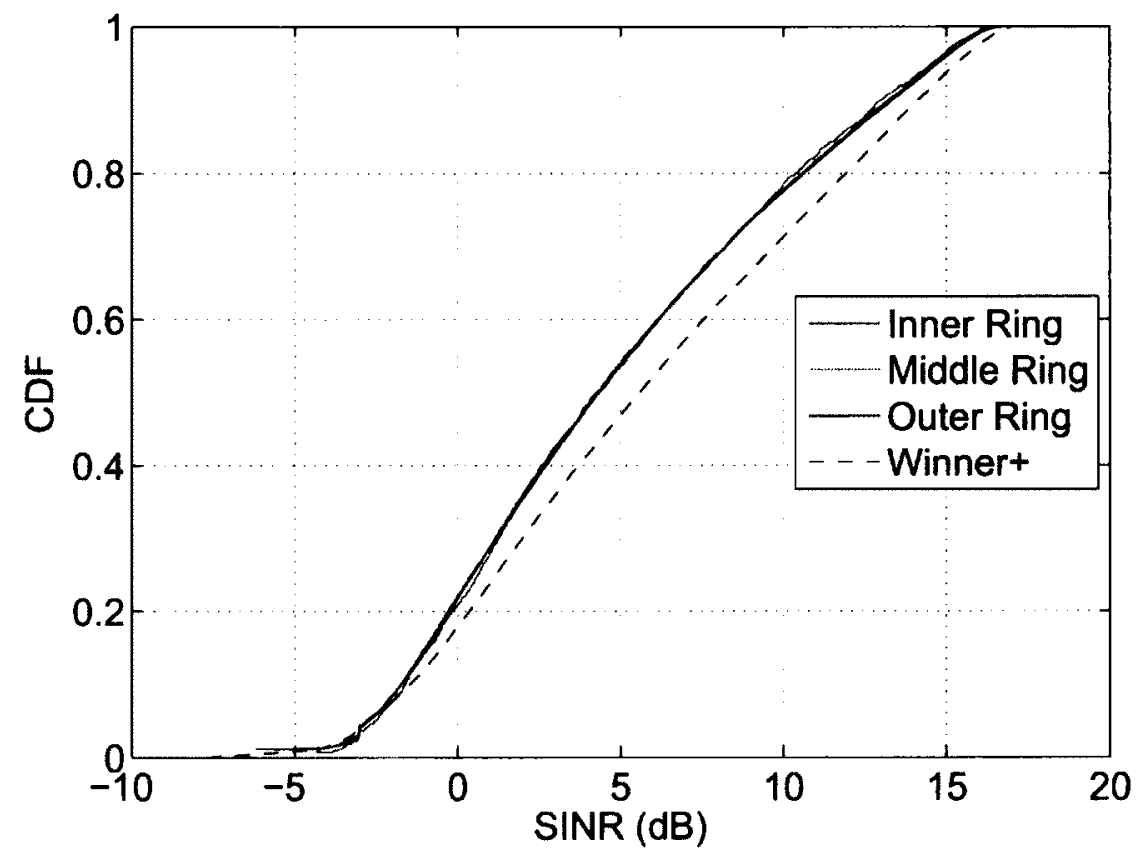

Figure 4.3.3: SINR curves with wrap-around. 
a certain percentage of UTs are distributed uniformly within three chosen hotspots, and the remaining users are distributed with uniform probability anywhere in the network. The UT concentration in the hotspots is chosen to be approximately double the concentration compared to non-hotspot areas. We also present two types of results:

- Instantaneous results showing how many cells were deactivated immediately following the execution of the algorithm. Although we call these results instantaneous, we could also consider them as time-averaged results if the UT positions (or in practice, SINR distributions) given as input to the algorithm are chosen based on statistical UT distribution during a particular time intervals throughout the day.

- Outage probability over a one-hour time period, which is generated by fixing the average number of UTs at a specific value and allowing UTs to enter and leave the network. New UTs enter the network according to a Poisson process, and the time for which they remain in the network is exponentially distributed with a mean of 1 minute. 


\section{Chapter 5}

\section{Simulation Results and Performance Analysis}

In this chapter, we present and discuss the results which were obtained by simulating the algorithms described in Chapter 3 in the scenarios described in Chapter 4 . We start by evaluating the algorithms in a regular hexagonal cell layout in Sections 5.1 and 5.2, which cover the constant interference and dynamic interference environments, respectively. We also discuss the implications of varying levels of energy consumption at different BSs in Section 5.3. We then move on to non-regular cell layouts in Section 5.4. Finally, we analyze the trade-offs between energy savings and user satisfaction in Section 5.5. For simplicity and ease of comparison between results, the performance curves found in the results are expressed as percentage of energy saved, which corresponds to the ratio of cells which have been switched off in the network. We present the tabulated raw simulation data alongside the figures in order to also allow easy comparison of the absolute number of cells which were switched off.

\subsection{Results for Schemes with Constant Interference}

Table 5.1.1 compares the results obtained by CZ (Algorithm 2.1), ECZ (Algorithm 3.1), and the optimal solution from the BILP formulation simulated with uniform and hotspot UT distributions using the worst-case interference assumption. 


\begin{tabular}{ccccccc} 
& \multicolumn{2}{c}{ Cell zooming } & \multicolumn{2}{c}{ Enhanced cell zooming } & \multicolumn{2}{c}{ Optimal solution } \\
\hline Num. of UTs & Uniform & Hotspots & Uniform & Hotspots & Uniform & Hotspots \\
\hline 285 & 1.04 & 1.36 & 8.72 & 12.4 & 10.52 & 14.04 \\
342 & 0.76 & 1.28 & 6.40 & 9.64 & 7.96 & 11.8 \\
399 & 0.52 & 0.88 & 4.24 & 7.36 & 5.88 & 9.64 \\
456 & 0.20 & 0.40 & 3.04 & 5.24 & 4.52 & 6.96 \\
513 & 0.12 & 0.12 & 2.08 & 4.40 & 3.92 & 6.32 \\
\hline
\end{tabular}

Table 5.1.1: Simulation results with regular hexagonal cell layout with 57 cells and constant interference for uniform and hotspot UT distributions. Results represent the number of cells which were switched off.

We note that the results for the $\mathrm{CZ}$ algorithm were obtained using our simulator, which takes into account interference. It can be seen that there is a big improvement going from $\mathrm{CZ}$ to $\mathrm{ECZ}$, and a further improvement with the BILP solution. Figures 5.1.1 and 5.1.2, which plot the results for the uniform and hotspot scenarios respectively, show that the performance improvement is similar in both cases and is relatively consistent across different numbers of UTs. The BILP solutions were obtained in MATLAB using the MOSEK toolbox, which was able to calculate the solution within seconds on a machine with a quad-core $3.4 \mathrm{GHz}$ processor and $8 \mathrm{~GB}$ of RAM. However, when the number of UTs exceeded 513 (9 UTs per cell), it would fail to generate a solution.

\subsection{Results for Schemes with Dynamic Interference}

Table 5.2.1 compares the results obtained by IACZ (Algorithm 3.2) and IAGA simulated with uniform and hotspot UT distributions where interference is a function of the set of active cells. The uniform and hotspot scenarios are plotted in Figure 5.2.1 and Figure 5.2.2, respectively. 


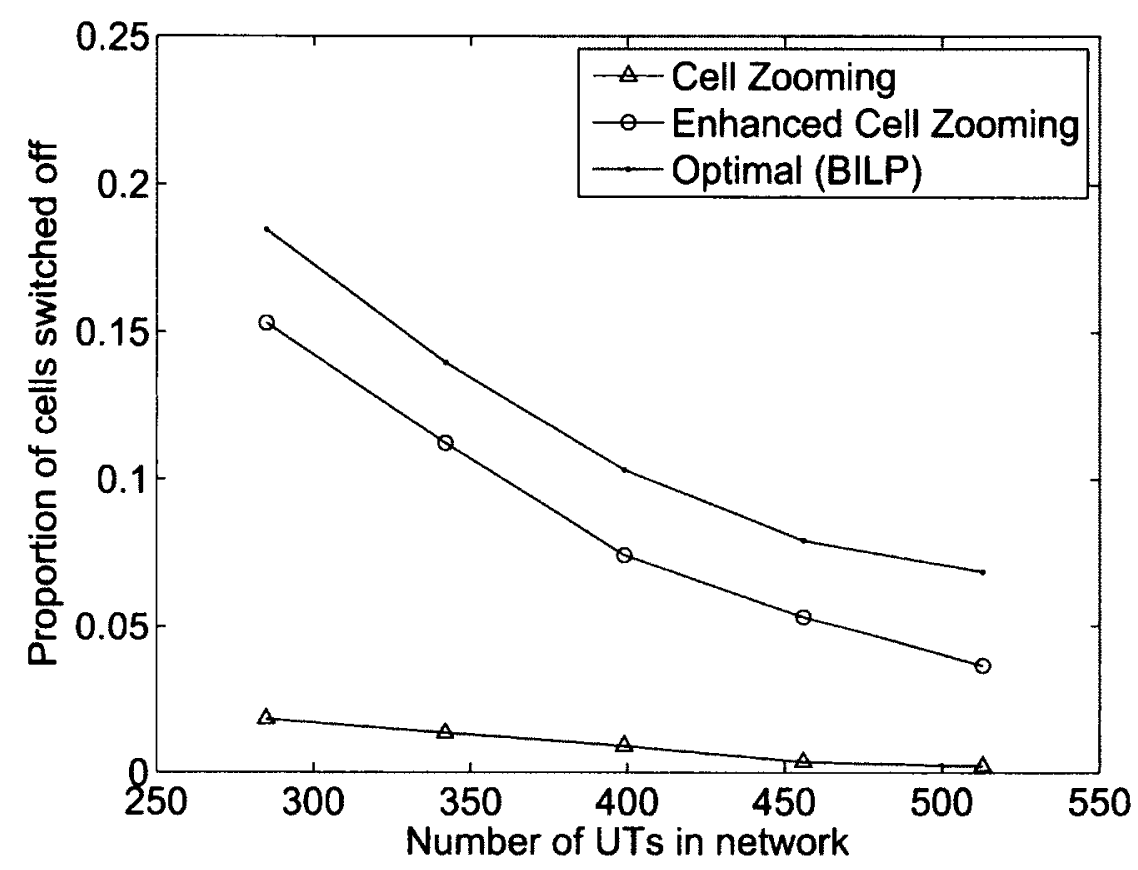

Figure 5.1.1: Plot of simulation results with regular hexagonal cell layout with 57 cells and constant interference for uniform UT distribution. Results represent the proportion of cells which were switched off.

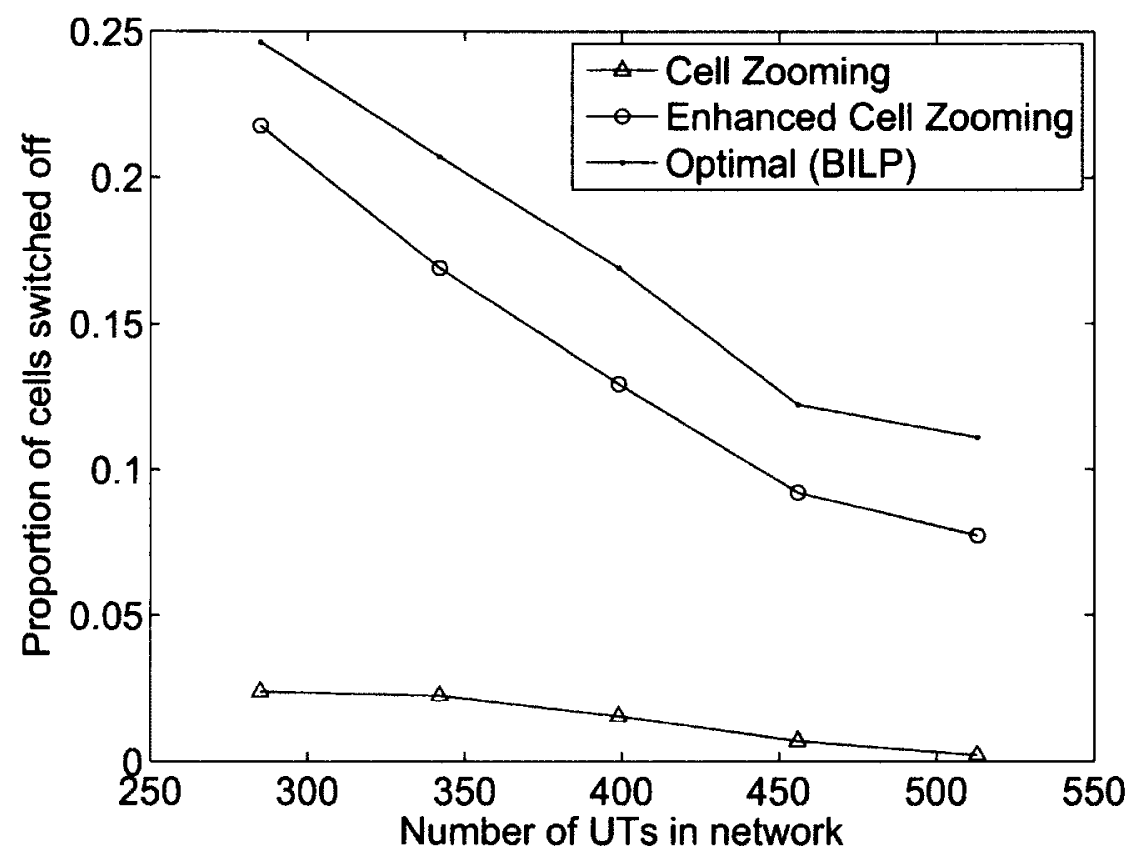

Figure 5.1.2: Plot of simulation results with regular hexagonal cell layout with 57 cells and constant interference for hotspot UT distribution. Results represent the proportion of cells which were switched off. 
Interference-aware cell zooming Interference-aware GA

\begin{tabular}{ccccc}
\hline Number of UTs & Uniform & Hotspots & Uniform & Hotspots \\
\hline 456 & 40.16 & 39.76 & 41.56 & 41.36 \\
570 & 35.44 & 35.12 & 36.92 & 36.56 \\
684 & 29.88 & 30.4 & 32.24 & 32.4 \\
798 & 23.84 & 25 & 26.48 & 26.84 \\
912 & 18.72 & 18.04 & 21.24 & 20.84 \\
1026 & 14 & 11.44 & 15.96 & 14.28 \\
1140 & 8.76 & 7.48 & 11.4 & 9.2 \\
1254 & 4.6 & 3.96 & 5.96 & 5.04 \\
\hline
\end{tabular}

Table 5.2.1: Simulation results with regular hexagonal cell layout with 57 cells and dynamic interference for uniform and hotspot UT distributions. Results represent the number of cells which were switched off.

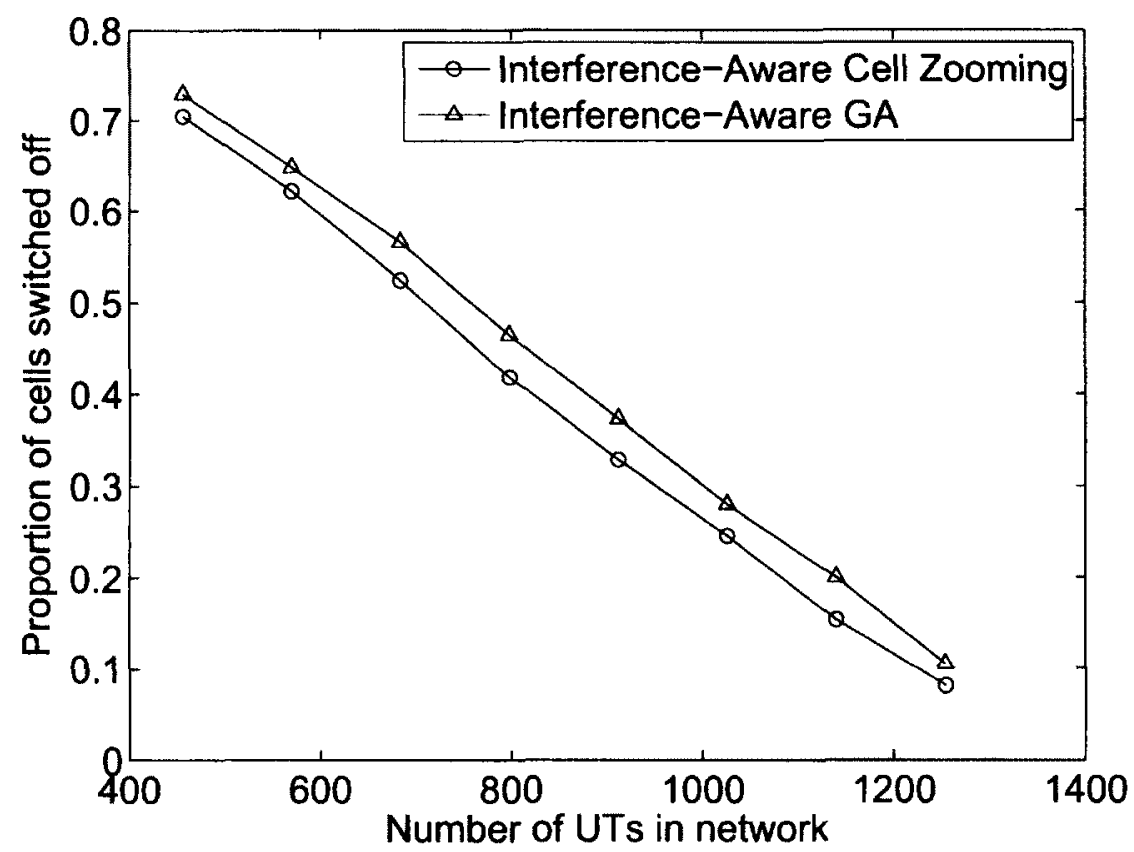

Figure 5.2.1: Plot of simulation results with regular hexagonal cell layout with 57 cells and dynamic interference for uniform UT distribution. Results represent the proportion of cells which were switched off. 


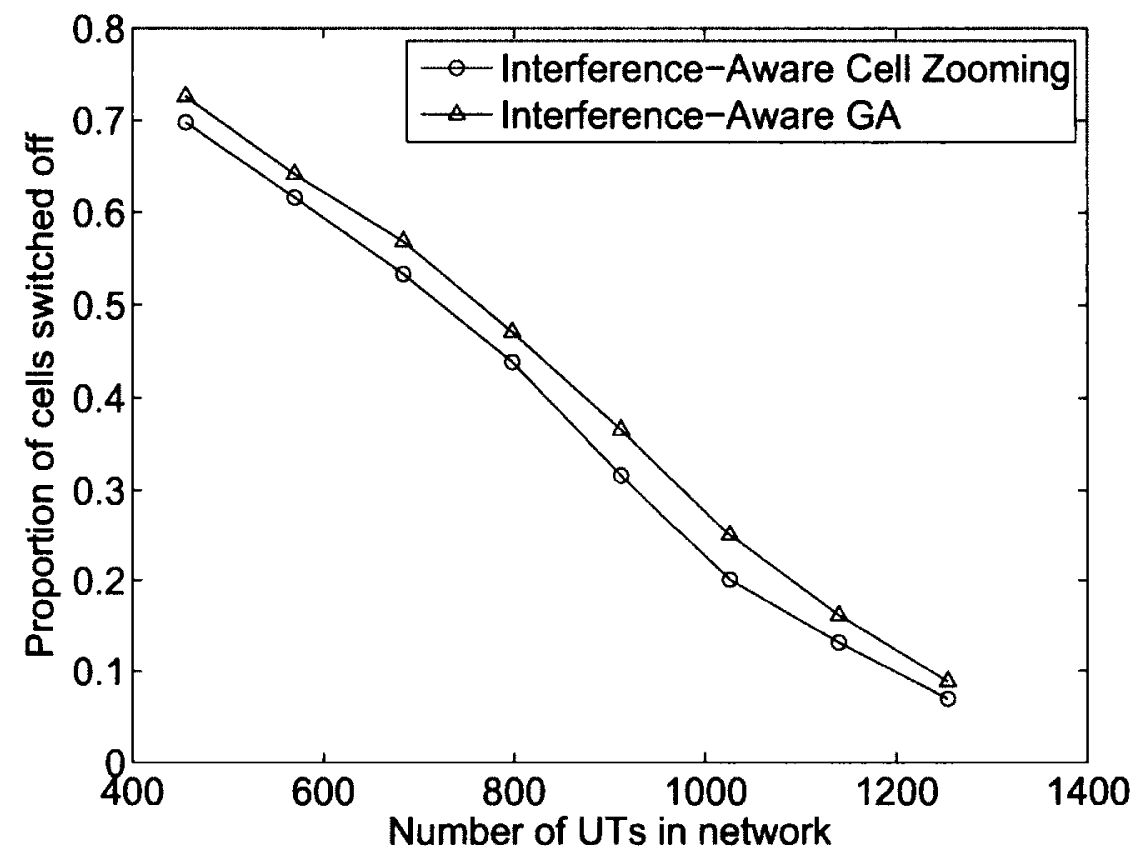

Figure 5.2.2: Plot of simulation results with regular hexagonal cell layout with 57 cells and dynamic interference for hotspot UT distribution. Results represent the proportion of cells which were switched off.

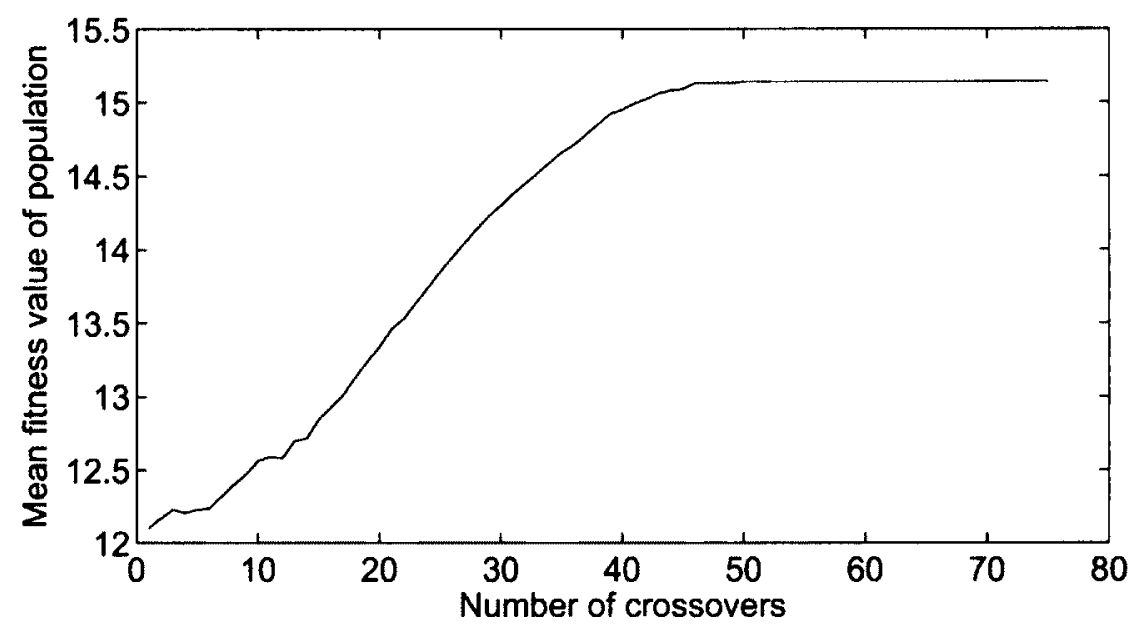

Figure 5.2.3: Plot showing IAGA convergence with an initial population of 57 . 
The IAGA was set up with an initial population of 57 random orderings, and reproduction was done by randomly selecting 8 solutions from the population and replacing the two lowest-fitness solutions with the offspring of the 2 highest-fitness solutions after doing a PMX crossover. The mutation operator was not used, since it did not result in any improvements in our tests. Using these parameters, the population converges after about 70 crossover operations, as can be seen in Figure 5.2.3. Comparing the performance of the IAGA with the IACZ, which is a single-iteration interference-aware heuristic, we are able to see how much of an improvement is gained by using a GA to search through different orderings to find the best solution.

We observe from the results obtained by both of the interference-aware algorithms in Table 5.2.1 that many more cells have been switched off when compared to the results obtained by the non-interference-aware algorithms presented in Table 5.1.1. This is because if worst-case interference is always considered, it becomes much more difficult to hand off UTs from one cell to a neighbouring cell due to the high interference which causes low spectral efficiency. However, if the spectral efficiency of a UT with a neighbouring cell is re-calculated by ignoring the received power from the cell with which it is currently associated, it allows for more flexibility in handing off UTs which then results in more cells being switched off. It is also seen by both Tables 5.2.1 and 5.1.1 that choosing which BSs to shut off becomes harder as the number of UTs increases. Although the numerical values of the number of cells switched off decreases as the number of UTs increases, the percentage gap between ECZ (Algorithm 3.1) and the optimal BILP solution increases, as does the gap between IACZ (Algorithm 3.2) and IAGA. This is due to the fact that a micro-cell environment is heavily interference-limited, and also that the UTs only require a certain minimum rate in order to be satisfied. This is made more clear in the extreme situation where 
there is only one active UT in the network and only a single BS will be needed in order to satisfy the demand. Due to the dense cell deployment, any of the available BSs will be able to satisfy the single UT if all the other BSs are switched off, due to the high spectral efficiency which is a result of both close proximity and the lack of interference.

\subsection{Results with Variable Energy Consumption at BSs}

In this section, we compare the performance of the ECZ and IAGA in the variable energy consumption scenario where a random set of 9 BSs is assigned an energy consumption weight of 2 , which implies that they consume double the energy compared to the remaining 10 BSs. The results are presented in Table 5.3.1, and the results for the uniform and hotspot UT distribution are plotted in Figure 5.3.1 and Figure 5.3.2, respectively. Intuitively, it can be realized that if the different energy consumption levels across cells are not taken into account by the algorithms, the plots presented in this section should simply be identical to those in the previous section but scaled by the average energy consumption of all the cells. For easy comparison, we have included those scaled results in the plots that follow.

In both Figure 5.3.1 and Figure 5.3.2 it can be seen that the results generated by IACZ in the variable consumption are indeed comparable to the scaled results from the previous scenario with uniform energy consumption. However, this is not the case with IAGA, where the performance of the algorithm in the variable energy consumption scenario surpasses the scaled results from the previous uniform energy consumption scenario. This shows that the performance advantage of IAGA grows with respect to IACZ in this scenario, since it is able to strategically select which cells to switch off based on the total energy savings rather than treating all cells in 
Interference-aware cell zooming Interference-aware GA

\begin{tabular}{ccccc}
\hline Number of UTs & Uniform & Hotspots & Uniform & Hotspots \\
\hline 456 & 59.72 & 59 & 62.64 & 63.44 \\
570 & 52.32 & 52.92 & 55.92 & 56.56 \\
684 & 43.76 & 44.4 & 47.68 & 47.52 \\
798 & 35.92 & 37.64 & 40.28 & 41.8 \\
912 & 27.72 & 29.96 & 32.48 & 35.28 \\
1026 & 19.84 & 19.16 & 24.64 & 24.68 \\
1140 & 13.12 & 11.18 & 17.84 & 14.8 \\
1254 & 7.48 & 6.24 & 9.92 & 8.12 \\
\hline
\end{tabular}

Table 5.3.1: Simulation results with regular hexagonal cell layout with 57 cells, dynamic interference, and variable energy consumption for uniform and hotspot UT distributions. Results represent the energy saved relative to a single energy-efficient cell.

the same way.

\subsection{Results for Springwald Layout}

In this section, we compare the performance of the ECZ and IAGA using the Springwald cell layout. The results with the Springwald layout are presented in Table 5.4.1, and the results for the uniform and hotspot UT distribution are plotted in Figure 5.4.1 and Figure 5.4.2, respectively. For this scenario, we ran the simulations with a reduced number of UTs when compared to the previous scenarios, since there are only 36 cells ( 12 cites) as opposed to 57 cells ( 19 cells). The performance trend of both algorithms is similar to the previous scenarios, but it can be seen that IAGA has a relatively larger performance lead in the non-regular Springwald layout. 


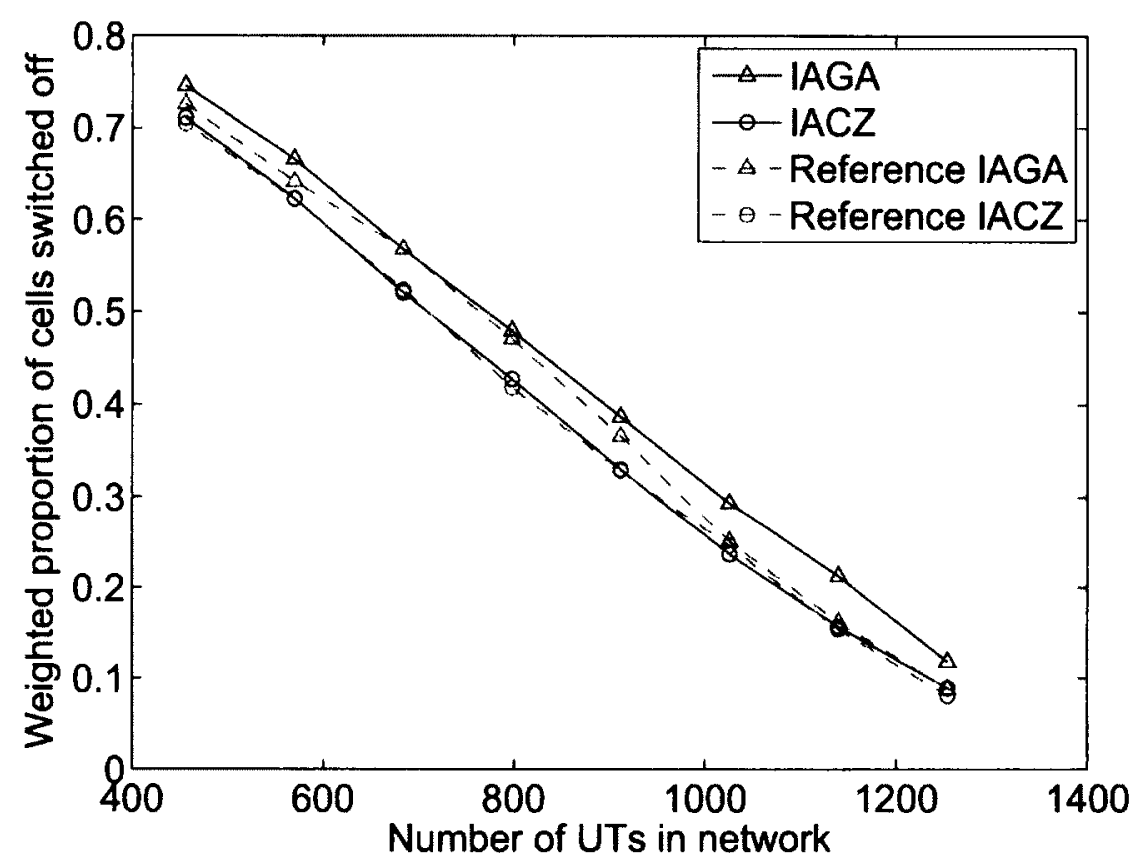

Figure 5.3.1: Plot of simulation results with regular hexagonal cell layout with 57 cells, variable energy consumption, dynamic interference, and uniform UT distribution. Results represent the weighted proportion of cells switched off.

Interference-aware cell zooming Interference-aware GA

\begin{tabular}{ccccc}
\hline Number of UTs & Uniform & Hotspots & Uniform & Hotspots \\
\hline 342 & 22.72 & 23.4 & 24.4 & 25.08 \\
456 & 16.72 & 16.92 & 18.76 & 18.96 \\
570 & 8.64 & 9.2 & 11 & 12.32 \\
684 & 4 & 2.96 & 5 & 3.92 \\
\hline
\end{tabular}

Table 5.4.1: Simulation results with Springwald cell layout and dynamic interference for uniform and hotspot UT distribution. Results represent the number of cells which were switched off. 


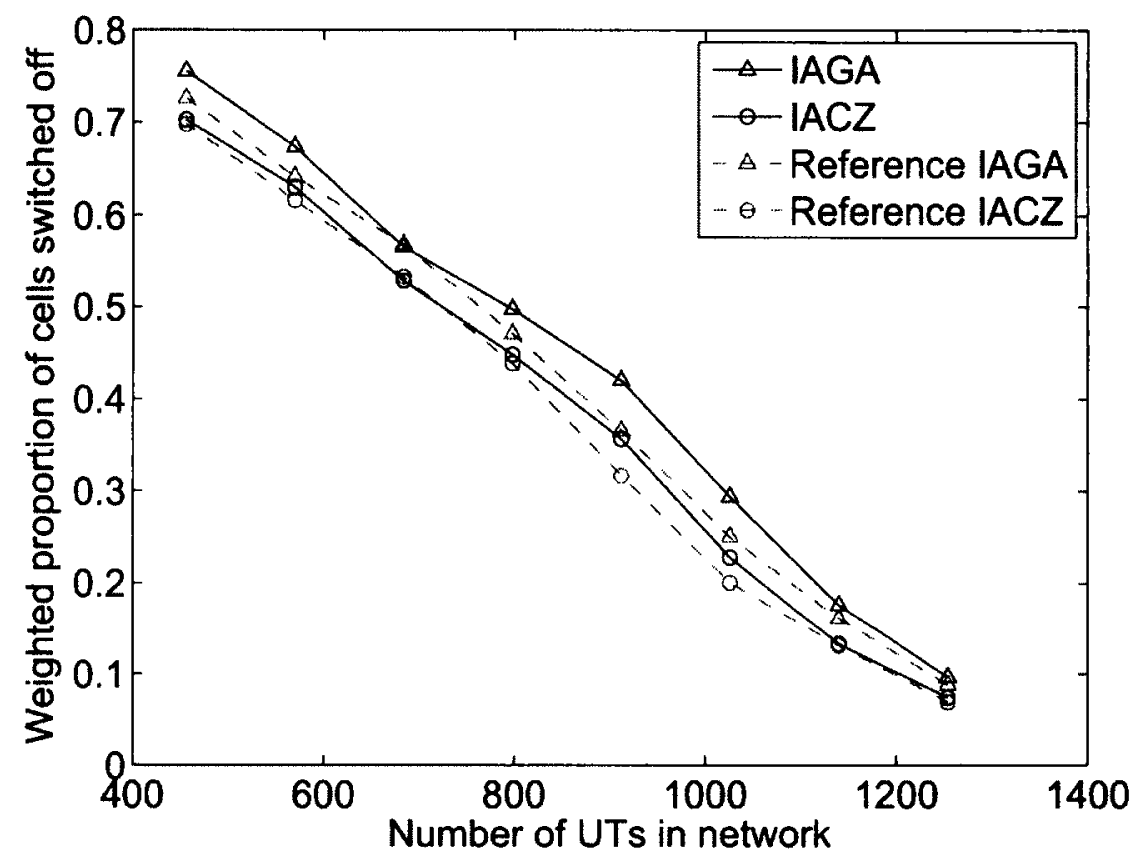

Figure 5.3.2: Plot of simulation results with regular hexagonal cell layout with 57 cells, variable energy consumption, dynamic interference, and hotspot UT distribution. Results represent the weighted proportion of cells switched off.

\subsection{Trade-offs Between Energy Saving and User Satisfaction}

In order to evaluate the trade-off between energy saving and user satisfaction, we ran simulations with a UT traffic model as described in Section 4.4. In the performance figures presented in this section, the vertical axis represents energy savings in the same way as the figures presented in previous sections. However, the horizontal axis represents the ratio of UTs whose minimum rate requirements were not satisfied by the network to the total number of UTs which were simulated. The figures in this section give an idea of the nature of the trade-off between energy saving and user satisfaction.

We first present the results for the regular hexagonal cell layout scenario. The raw simulation data is tabulated in Table 5.5.1 and Table 5.5.2, and the outage curves 


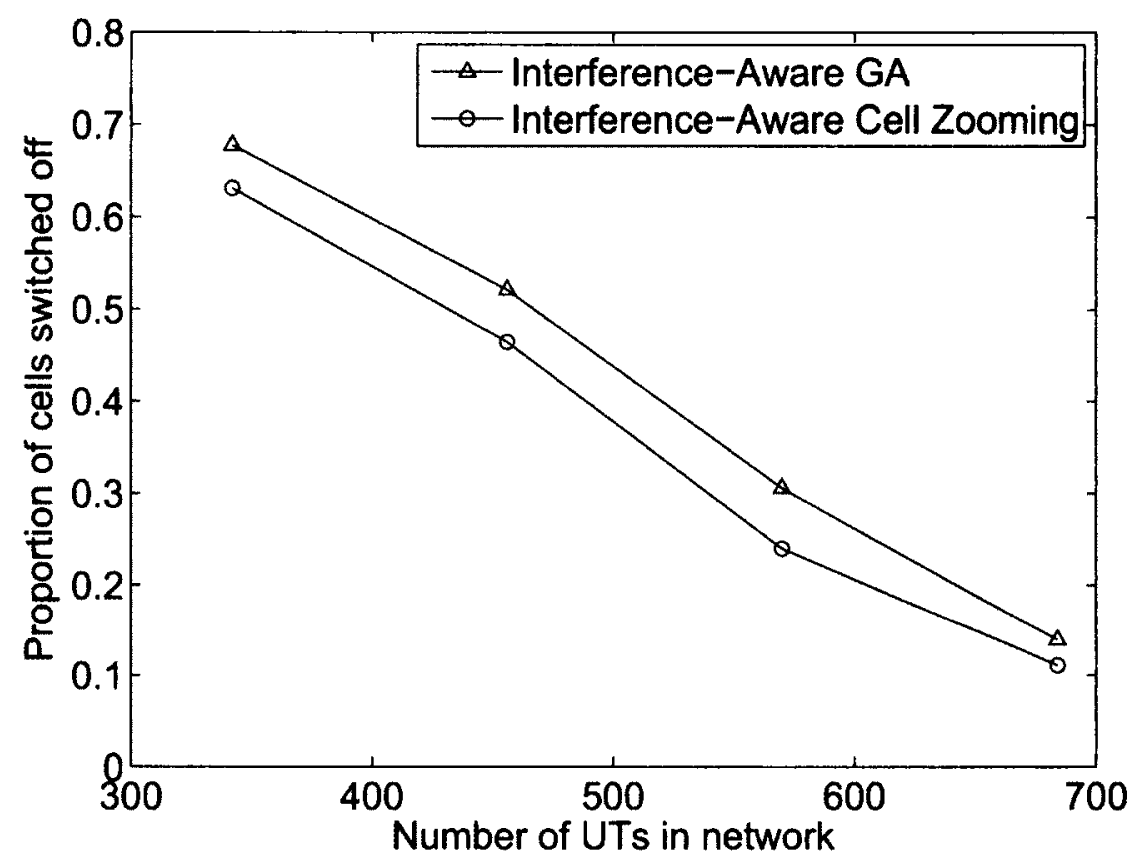

Figure 5.4.1: Plot of simulation results with Springwald cell layout and dynamic interference for uniform UT distribution. Results represent the proportion of cells which were switched off.

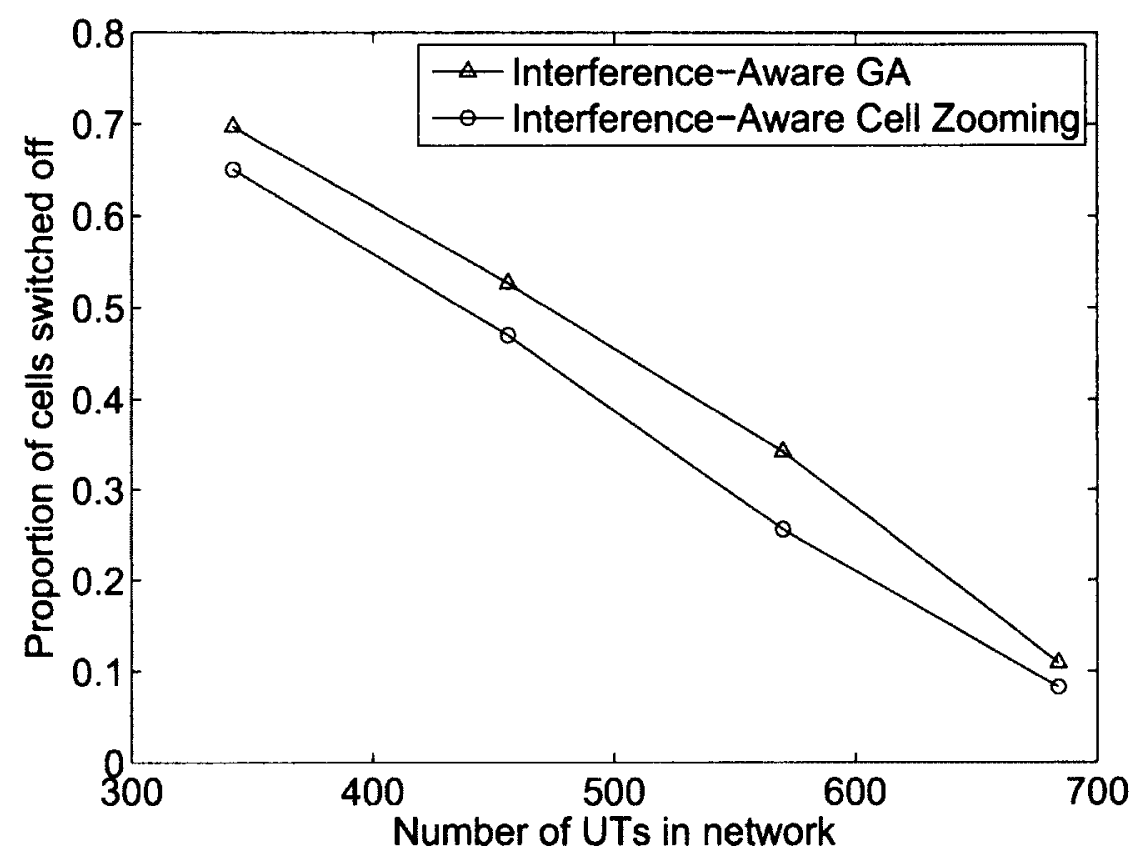

Figure 5.4.2: Plot of simulation results with Springwald cell layout and dynamic interference for hotspot UT distribution. Results represent the proportion of cells which were switched off. 
are plotted in Figure 5.5.1 and Figure 5.5.2 for the results obtained with uniform and hotspot UT distributions, respectively. In order to generate these results, we varied the parameter $\alpha$, where $\alpha \in[0,1]$, in order to cap the maximum bandwidth utilization of the cells during the execution of the cell switch-off algorithm as was done in [1]. This effectively reserves some spare bandwidth at each cell and restricts the number of cells which can be turned off, allowing us to tune the algorithm to operate at different trade-off regions between energy saving and user satisfaction. It can be seen from the figures that the curves generated by IAGA appear to the left of IACZ in both figures. This indicates that in the regions where IAGA switches off the same number of cells as IACZ, it is able to achieve higher user satisfaction. Another way of interpreting the results is that IAGA can achieve higher energy savings than IACZ without any additional penalty in user satisfaction. A final observation is that in both Figures 5.5.1 and 5.5.2, and especially in Figure 5.5.2, the user satisfaction penalty at the left-hand side of the plot for the first few cells that are switched off are negligible. The IAGA also performs quite well in this region. This is a positive sign, since it shows that some energy can easily be saved without any impact to the user experience.

Finally, for thoroughness, we present the results for the Springwald cell layout scenario. The raw simulation data is tabulated in Table 5.5.3 and Table 5.5.4, and the outage curves are plotted in Figure 5.5.3 and Figure 5.5.4 for the results obtained with uniform and hotspot UT distributions, respectively. We observe that the performance trends are similar to the regular hexagonal cell layout scenario, but we observe especially in Figure 5.5.3 that the performance advantage of IAGA over IACZ is larger when using the Springwald layout. 
Cells switched off UTs simulated UTs unsatisfied

\begin{tabular}{ccccccc}
\hline$\alpha$ & IAGA & IACZ & IAGA & IACZ & IAGA & IACZ \\
\hline 1 & 31 & 27 & 41796 & 41840 & 4912 & 4395 \\
0.95 & 29 & 26 & 41978 & 41441 & 4846 & 3444 \\
0.9 & 27 & 26 & 41852 & 41730 & 3546 & 3628 \\
0.85 & 26 & 22 & 41751 & 41534 & 2627 & 1591 \\
0.80 & 23 & 21 & 41899 & 41891 & 1910 & 1695 \\
0.75 & 21 & 18 & 41689 & 41667 & 1116 & 952 \\
0.70 & 17 & 13 & 41330 & 41342 & 633 & 337 \\
0.65 & 14 & 11 & 41953 & 41892 & 238 & 192 \\
0.60 & 10 & 7 & 41221 & 42027 & 112 & 51 \\
0.55 & 4 & 3 & 41957 & 41496 & 22 & 18 \\
0.50 & 2 & 2 & 41551 & 41601 & 7 & 4 \\
\hline
\end{tabular}

Table 5.5.1: Trade-off between energy saving and user satisfaction with uniform distribution and average of 684 UTs in network.

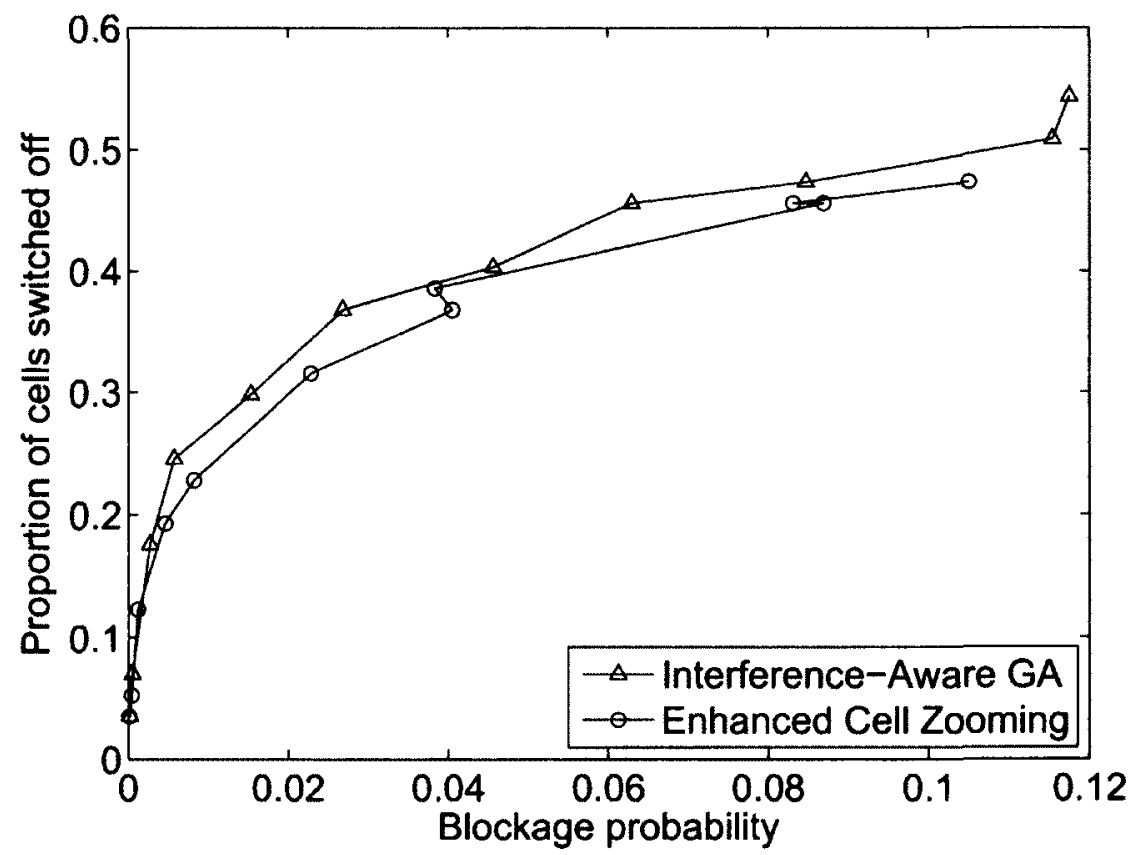

Figure 5.5.1: Plot of simulation results with a regular hexagonal layout for uniform UT distribution with 684 UTs. Results represent the proportion of users blocked as a function of the proportion of cells were switched off. 


\begin{tabular}{ccccccc}
\multicolumn{3}{c}{ Cells switched off } & \multicolumn{2}{c}{ UTs simulated } & \multicolumn{2}{c}{ UTs unsatisfied } \\
\hline$\alpha$ & IAGA & IACZ & IAGA & IACZ & IAGA & IACZ \\
\hline 1 & 32 & 31 & 41885 & 41718 & 4779 & 4401 \\
0.95 & 30 & 30 & 41793 & 41811 & 3809 & 4509 \\
0.9 & 28 & 24 & 41595 & 41448 & 2710 & 1751 \\
0.85 & 26 & 24 & 41850 & 41890 & 2176 & 1665 \\
0.80 & 24 & 21 & 41844 & 41732 & 1576 & 1285 \\
0.75 & 22 & 20 & 41657 & 41978 & 1081 & 1053 \\
0.70 & 20 & 18 & 41867 & 41725 & 996 & 733 \\
0.65 & 18 & 15 & 41705 & 41877 & 802 & 913 \\
0.60 & 14 & 10 & 42102 & 41740 & 507 & 320 \\
0.55 & 13 & 8 & 41493 & 41591 & 350 & 328 \\
0.50 & 9 & 7 & 42017 & 41210 & 340 & 302 \\
\hline
\end{tabular}

Table 5.5.2: Trade-off between energy saving and user satisfaction with hotspot distribution and average of 684 UTs in network.

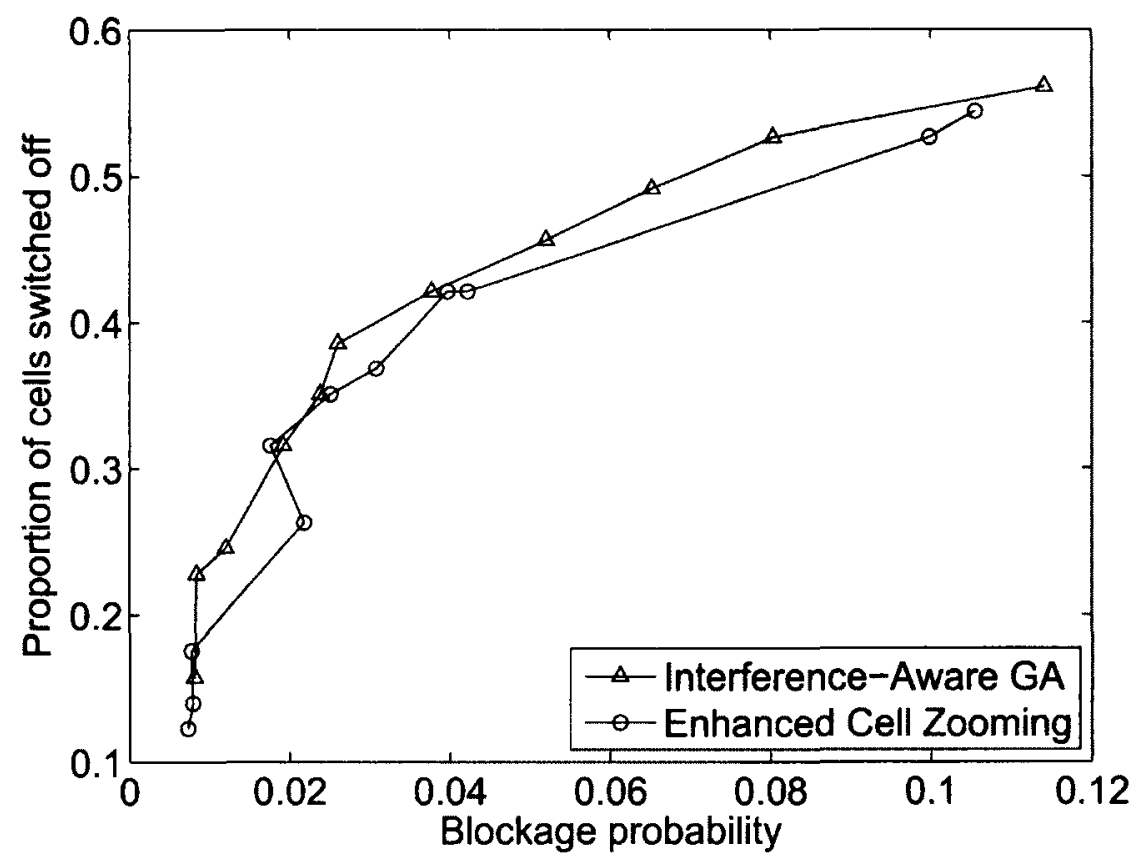

Figure 5.5.2: Plot of simulation results with a regular hexagonal layout for hotspot UT distribution with 684 UTs. Results represent the proportion of users blocked as a function of the proportion of cells were switched off. 
Cells switched off UTs simulated UTs unsatisfied

\begin{tabular}{ccccccc}
\hline$\alpha$ & IAGA & IACZ & IAGA & IACZ & IAGA & IACZ \\
\hline 1 & 24 & 20 & 21887 & 22185 & 2533 & 2400 \\
0.95 & 22 & 19 & 21909 & 22211 & 1720 & 1425 \\
0.9 & 21 & 18 & 22056 & 22129 & 1201 & 1268 \\
0.85 & 21 & 18 & 22208 & 22156 & 1422 & 850 \\
0.80 & 19 & 15 & 22231 & 21913 & 715 & 395 \\
0.75 & 17 & 13 & 22046 & 21503 & 436 & 277 \\
0.70 & 15 & 13 & 21973 & 22279 & 251 & 285 \\
0.65 & 13 & 8 & 22169 & 22096 & 93 & 97 \\
0.60 & 10 & 9 & 22097 & 22005 & 50 & 39 \\
0.55 & 9 & 7 & 22193 & 22066 & 56 & 52 \\
0.50 & 8 & 8 & 22040 & 21711 & 51 & 53 \\
\hline
\end{tabular}

Table 5.5.3: Trade-off between energy saving and user satisfaction with uniform UT distribution and average of 361 UTs in network with Springwald cell layout with 57 cells.

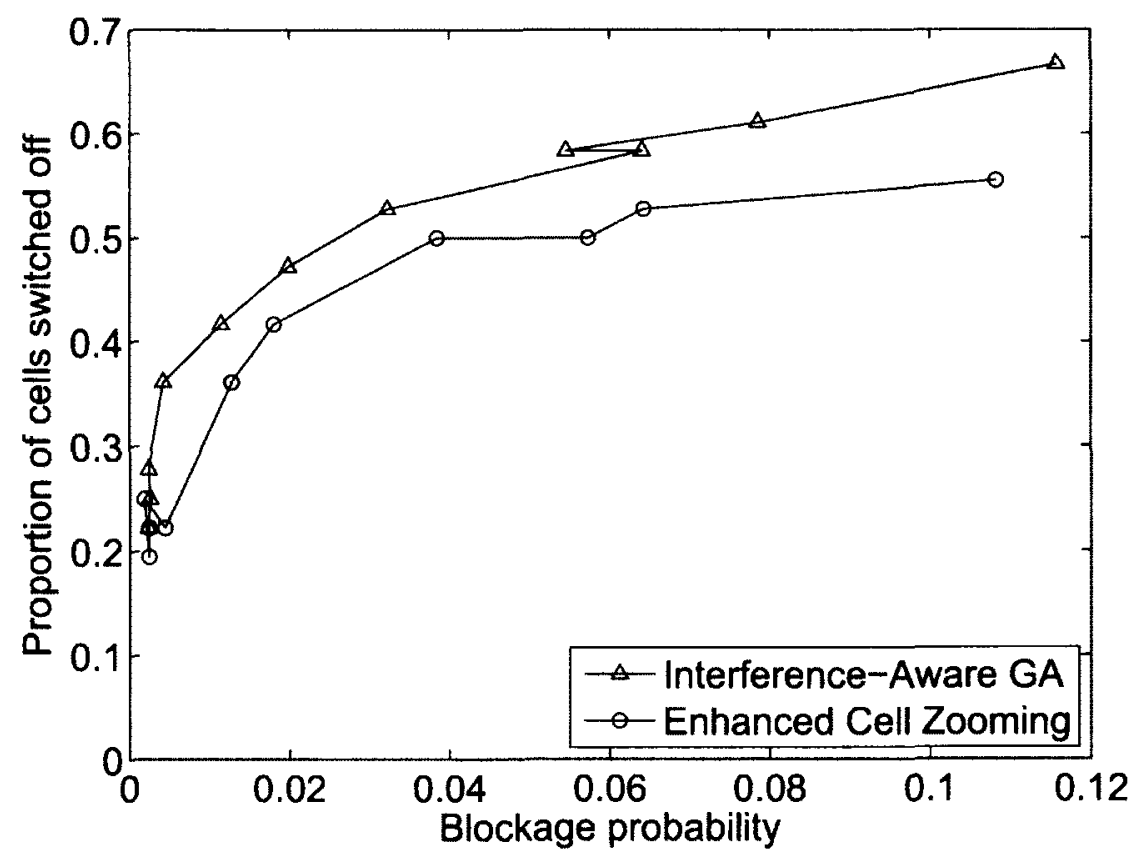

Figure 5.5.3: Plot of simulation results with Springwald cell layout with 57 cells for uniform UT distribution with 361 UTs. Results represent the proportion of users blocked as a function of the proportion of cells were switched off. 
Cells switched off UTs simulated UTs unsatisfied

\begin{tabular}{ccccccc}
\hline$\alpha$ & IAGA & IACZ & IAGA & IACZ & IAGA & IACZ \\
\hline 1 & 22 & 20 & 26287 & 26077 & 3561 & 2699 \\
0.95 & 21 & 20 & 26555 & 26264 & 3168 & 2781 \\
0.9 & 19 & 17 & 26344 & 26698 & 1990 & 2284 \\
0.85 & 17 & 13 & 26502 & 26314 & 2025 & 947 \\
0.80 & 13 & 9 & 26431 & 26556 & 854 & 637 \\
0.75 & 10 & 8 & 26520 & 26553 & 478 & 588 \\
0.70 & 8 & 7 & 26321 & 26299 & 364 & 413 \\
0.65 & 8 & 6 & 26525 & 26488 & 419 & 464 \\
0.60 & 6 & 5 & 26545 & 26242 & 446 & 444 \\
0.55 & 4 & 3 & 26330 & 26178 & 444 & 256 \\
0.50 & 3 & 2 & 26105 & 26557 & 228 & 322 \\
\hline
\end{tabular}

Table 5.5.4: Trade-off between energy saving and user satisfaction with hotspot UT distribution and average of 432 UTs in network with Springwald cell layout with 57 cells.

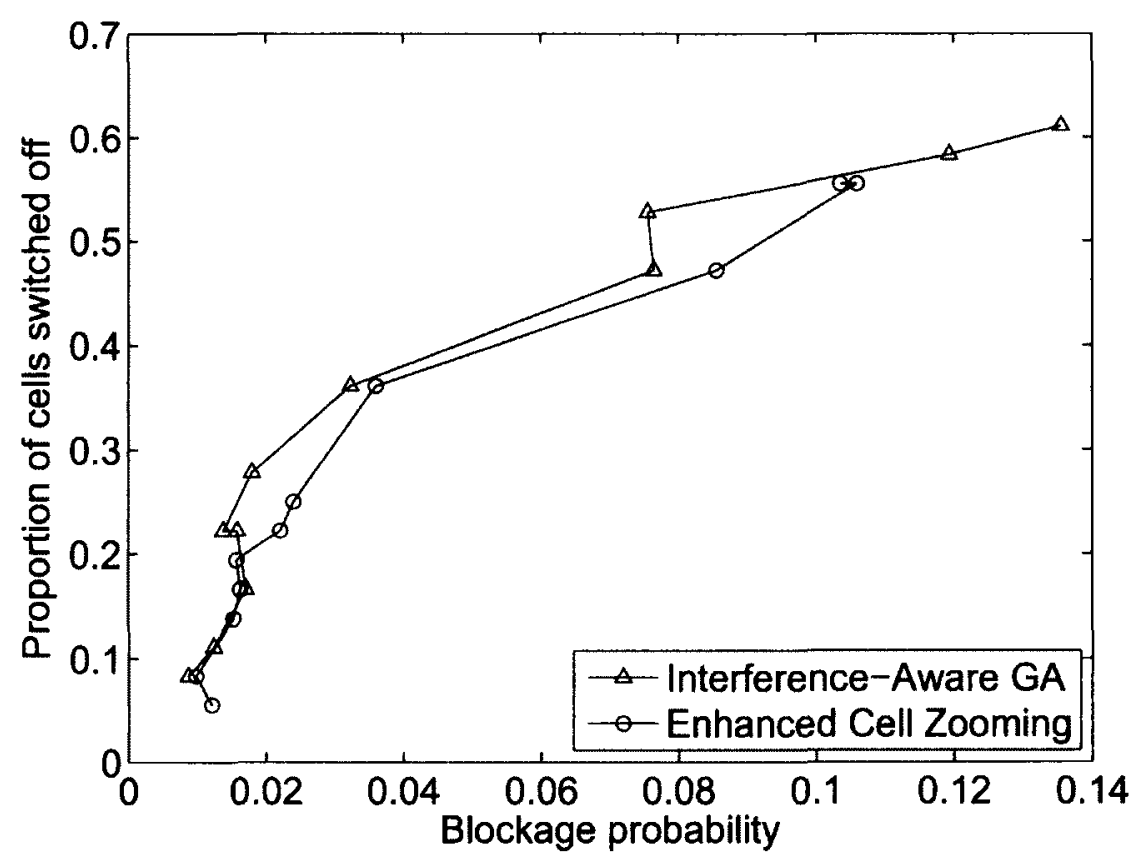

Figure 5.5.4: Plot of simulation results with Springwald cell layout with 57 cells for hotspot UT distribution with 432 UTs. Results represent the proportion of users blocked as a function of the proportion of cells were switched off. 


\subsection{Implementation and Complexity}

The main challenge associated with the implementation of schemes which require inter-cell communication of symbol-level data, such as ICIC and CoMP, lies in the requirement of a low-latency communication link between neighbouring cells. In order to address this challenge, future LTE networks will support a new interface called X2, which will enable mesh interconnectivity between cells [42]. However, as discussed in Chapter 4, our cell switch-off schemes operate on a much longer time scale than these algorithms, and therefore the latency requirements are not as stringent. Consequently, our cell switch-off scheme would not even require X2 links and could instead operate using the IP backhaul. For the BILP and ECZ schemes, described in Sections 3.1 and 3.2, the only channel state information (CSI) required is the SINRs of the UTs with those cells that are able to satisfy their minimum rate requirement. The CSI required by the IACZ and IAGA schemes, described in Sections 3.3 and 3.4, is the power received by all UTs from all the cells within their range. This information could be collected relatively easily over the control channels and then transmitted over the IP backhaul to a central entity which can execute the algorithm.

While BILP is NP-hard, all of the other algorithms which we presented, namely ECZ, IACZ, and IAGA, have linear complexity. However, IACZ and IAGA require additional computations when compared to ECZ since they are interference-aware and therefore need to frequently re-calculate the spectral efficiencies of all the UTs. IAGA also requires more computations when compared to IACZ, based on the population size and termination condition. Although the complexity of IAGA is still linear, it is shifted by a constant due to the extra computations. However, in the context of cell switch-off this is not of big importance since, as mentioned above, our 
scheme operates on a relatively long time interval. Furthermore, in absolute terms, the execution time of IAGA is not particularly long. For example, it takes about 90 seconds to execute IAGA with 684 users, compared to about 0.5 seconds to execute IACZ on a machine with a quad-core $3.4 \mathrm{GHz}$ processor and $8 \mathrm{~GB}$ of RAM. However, in our simulations, more than half of the time is spent by MATLAB (according to the profiler tool) in copying matrices since it is very inefficient at accessing structures and does not support pointer arrays, which forced us to repeatedly copy data out of structures into matrices before running computations. The execution time of IAGA could easily be reduced by implementing it in a more efficient language such as $\mathrm{C} / \mathrm{C}++$ and also including some additional enhancements such as the partial fitness function evaluation technique discussed in Section 2.3.2. 


\section{Chapter 6}

\section{Conclusions and Future Work}

\subsection{Summary and Discussion of Contributions}

We have shown that in some simplified scenarios, the cell switch-off problem can be formulated as a binary linear integer programming problem. However, even in the constant-interference scenario that we considered, the problem formulation can be turned into the bin-packing problem which is NP-hard. In more sophisticated system models, as in the scenario we considered where interference is made a function of BS configuration, or in other scenarios where advanced tools such as coordinated multiple point transmission/reception (CoMP) or inter-cell interference coordination (ICIC) are taken into account, it is necessary to develop a suboptimal scheme which is computationally efficient. After improving upon a reference heuristic with linear complexity for the non-interference-aware scenario, we extended the heuristic to be interference-aware while still maintaining linear complexity. We then further improved its performance by using a GA.

In addition to the partially matched crossover, we implemented the order crossover operator as in the example which we previously discussed in Section 3.4. However, it offered inferior performance to the partially matched crossover. We also implemented two customized crossover operators which we designed based on the order crossover but with a binary mask which was a function of the cells that were switched off us- 
ing the parent chromosomes. We found that these order crossover operators did not improve the results obtained from the partially matched crossover.

The performance advantage of the GA lies in the fact that it is free from having to follow a fixed ordering when turning off cells. Following a fixed ordering results in fewer cells being switched off, since virtually any single cell in the network can be switched off in periods of light traffic, and therefore making poor decisions in the early steps will impact the quality of the final solution. Each cell that is switched off has a different impact on the network based on the resulting spectral efficiency between the UTs and remaining cells in the network. This is why it is important for the algorithm to intelligently select the cells which will allow the maximum number of cells switched off (or maximum energy savings).

The simulation results in the variable-interference scenarios show that IAGA consistently produces better results than IACZ. We have also seen in the constantinterference case that the performance of ECZ is not very far behind the optimal BILP solution. This leads us to believe that the results generated by IAGA are likely to be relatively close to the optimal solution.

\subsection{Future Research Directions and Possible Extensions}

Cell switch-off is a research problem which is still in its early phases, and there are still many aspects of the problem which need to be investigated. Some future research directions and possible extensions are as follows:

\subsubsection{Cell Parameter Optimization}

Cell parameter optimization, which can control parameters such as transmit power, antenna tilt, or hand-off thresholds, can be integrated into cell switch-off 
schemes. This would allow future networks with cell switch-off to emulate the behaviour of CDMA networks with "cell breathing", where the coverage area of a cell expands and contracts based on the current load. This allows for a more spectrally efficient UT-to-cell assignment which improves the quality of service. As discussed in Chapter 2, there is already some existing work such as [14] dealing with the dynamic adjustment of cell hand-off thresholds for the purposes of load balancing, and this work could be adapted to be used in the context of cell switch-off along with other techniques such as power control and remote antenna tilting.

\subsubsection{Advanced Radio Access Networks}

Advanced techniques such as CoMP, multi-hop relaying, and ICIC can be integrated into the cell switch-off decision-making process in order to help in maintaining good coverage in areas where cells are switched off.

\subsubsection{Traffic Prediction and Machine Learning}

Traffic prediction mechanisms can be used to improve cell switch-off decisions. There are a number of advantages in following this approach. For example, machine learning can allow the network to learn from the association between historical UT distributions and the results of its previous cell switch-off decisions. This can reduce computational complexity, since the network can recognize UT distribution patterns which it had already seen in the past and make use of the "knowledge" which it accumulated from its previous decisions instead of needlessly repeating computationally expensive calculations. A further advantage would be that by anticipating UT traffic patterns in advance, the network could make more intelligent cell switch-off decisions, and could also make more frequent reconfigurations while avoiding frequent on/off 
transitions at specific cells since it could anticipate in advance how often each cell would need to be reconfigured.

\subsubsection{Parallel GAs}

We presented our GA-based scheme as a centralized scheme, due to the algorithm's requirement that the received power of all UTs in the network be given as input. However, it would be possible to modify the scheme to allow distributed execution of the existing algorithm across the BSs in the network. This would reduce computational time and negate the need for a central entity to perform the calcula-

tions. In fact, there has been an abundance of research in the last several years in the parallel execution of GAs, and one of the more current research trends has been in executing GAs on geographically separated clusters for applications such as grid computing (see Section 5.4.3 in [28]).

An implementation issue which is relevant to cell switch-off or any other networkwide algorithms in a large network is the question of whether the algorithm should be executed in one step for the entire network or if the network should be divided into small regions such that the algorithm can be executed in each region independently. In the latter case, a clustering algorithm would be needed in order to effectively divide the BSs into regions. Consequently, the algorithm would need to have some mechanism to deal with edge effects and would likely require some level of co-ordination between the regions.

\subsubsection{Multiple Power States and Frequency Bands}

Some other BS energy saving techniques which have been proposed include dynamic spectrum reduction, which reduces the spectrum available at a $\mathrm{BS}$, and dy- 
namic voltage adjustment, which allows a BS to save energy by reducing the voltage and clock speeds of its processing chips [17], [43]. These techniques could be used in conjunction with cell switch-off in order to obtain a better trade-off between energy efficiency and user satisfaction. Dynamic spectrum reduction in particular is a tool which could be used in order to reduce both energy consumption and inter-cell interference simultaneously.

Another issue related to dynamic spectrum reduction is how to deal with multiple frequency bands. Many wireless network operators have licenses in multiple frequency bands, such as $850 \mathrm{MHz}, 1700 \mathrm{MHz}$, and $1900 \mathrm{MHz}$ in North America, or $900 \mathrm{MHz}$, $1800 \mathrm{MHz}$, and $2100 \mathrm{MHz}$ in Europe. In fact, operators which have multiple licenses typically operate overlayed networks where antennas are deployed for both frequency bands at most BSs. Often, voice traffic is prioritized on the lower bands to allow more consistent coverage, whereas the upper bands are used more for extra data capacity. For this reason, it would be a good idea to extend this research to consider multiple frequency bands and how cells should be switched on or off in that scenario.

\subsubsection{Larger Scale Simulation}

In a future study which takes into account some new techniques such as the ones mentioned above, it would be interesting to do a more sophisticated performance analysis which includes uplink performance, more detailed UT models involving realistic data traffic and UT mobility, and more detailed BS energy consumption models. 


\section{References}

[1] Z. Niu, Y. Wu, J. Gong, and Z. Yang, "Cell zooming for cost-efficient green cellular networks," IEEE Communications Magazine, vol. 48, no. 11, pp. 74-79, November 2010.

[2] "Guidelines for evaluation of radio interface technologies for IMT-Advanced," ITU-R, Tech. Rep. M.2135-1, 2009.

[3] P. Gildert, "Power system efficiency in wireless communication," Applied Power Electronics Conference, 2006. [Online]. Available: http://www.apec-conf.org/ 2006/APEC_2006_SP2_1.pdf

[4] G. Ucoluk, "Genetic algorithm solution of the TSP avoiding special crossover and mutation," Intelligent Automation and Soft Computing, vol. 8, no. 3, pp. 265-272, 2002.

[5] "Energy efficiency good practices," Nokia Siemens Networks, May 2011. [Online]. Available: http://www.nokiasiemensnetworks.com/sites/default/files/ document/energy_efficiency_good_practices.pdf

[6] Z. Hasan, H. Boostanimehr, and V. K. Bhargava, "Green cellular networks: A survey, some research issues and challenges," IEEE Communications Surveys $\mathcal{B}$ Tutorials, vol. 13, no. 4, pp. 524-540, Fourth Quarter 2011.

[7] "Huawei whitepaper on energy efficiency and carbon reduction," White Paper, Huawei, May 2011. [Online]. Available: http://www.huawei.com/en/static/ hw-076768.pdf

[8] "Small cells - what's the big idea?" White Paper, Small Cell Forum, February 2012. [Online]. Available: http://smallcellforum.org/smallcellforum_resources/ pdfsend01.php?file=SCF-Small_Cells_White_Paper.pdf

[9] 3GPP TSG-RAN WG3 \#66 R3-100162, "Overview to LTE energy saving solutions to cell switch off/on," January 2010.

[10] 3GPP TSG-RAN WG3 \#66 R3-093103, "LTE energy saving solution proposal following discussions at RAN3\#65bis," November 2009. 
[11] A. M. Marsan and M. Meo, "Energy efficient wireless Internet access with cooperative cellular networks," Comput. Netw., vol. 55, no. 2, pp. 386-398, February 2011.

[12] X. Weng, D. Cao, and Z. Niu, "Energy-efficient cellular network planning under insufficient cell zooming," in IEEE Vehicular Technology Conference (VTC 2011Spring), May 2011, pp. 1-5.

[13] O. Arnold, F. Richter, G. Fettweis, and O. Blume, "Power consumption modeling of different base station types in heterogeneous cellular networks," in Future Network and Mobile Summit, June 2010, pp. 1-8.

[14] A. Lobinger, S. Stefanski, T. Jansen, and I. Balan, "Load balancing in downlink lte self-optimizing networks," in IEEE Vehicular Technology Conference (VTC 2010-Spring), May 2010, pp. 1-5.

[15] Antenna Interface Standards Group Standard No. AISG v2.0, "Control interface for antenna line devices," June 2006.

[16] A. B. Sediq, R. Schoenen, H. Yanikomeroglu, G. Senarath, and Z. Chao, "A novel distributed inter-cell interference coordination scheme based on projected subgradient and network flow optimization," in IEEE International Symposium on Personal, Indoor and Mobile Radio Communications (PIMRC 2011).

[17] O. Blume, H. Eckhardt, S. Klein, E. Kuehn, and W. M. Wajda, "Energy savings in mobile networks based on adaptation to traffic statistics," Bell Lab. Tech. J., vol. 15 , no. 2, pp. 77-94, September 2010.

[18] Y. Wei, Z. Zhao, and H. Zhang, "Dynamic energy savings in heterogeneous cellular networks based on traffic prediction using compressive sensing," in 11th International Symposium on Communications and Information Technologies (ISCIT), October 2011, pp. 460-465.

[19] M. Marsan, L. Chiaraviglio, D. Ciullo, and M. Meo, "Optimal energy savings in cellular access networks," in IEEE International Conference on Communications (ICC) Workshops, June 2009, pp. 1-5.

[20] A. M. Marsan, D. Chiaraviglio, D. Ciullo, and M. Meo, "Multiple daily base station switch-offs in cellular networks," in 4th International Conference on Communications and Electronics (ICCE 2012), August 2012.

[21] R. L. Rardin and R. Uzsoy, "Experimental evaluation of heuristic optimization algorithms: A tutorial," Journal of Heuristics, vol. 7, no. 3, pp. 261-304, May 2001. 
[22] T. W. Rondeau and C. W. Bostian, Artificial Intelligence in Wireless Communications. Norwood, Massachusetts: Artech House Publishers, 2009.

[23] A. He, K. K. Bae, T. R. Newman, J. Gaeddert, K. Kim, R. Menon, L. MoralesTirado, J. Neel, Y. Zhao, J. H. Reed, and W. H. Tranter, "A survey of artificial intelligence for cognitive radios," IEEE Transactions on Vehicular Technology, vol. 59, no. 4, pp. 1578-1592, May 2010.

[24] A. Galindo-Serrano and L. Giupponi, "Distributed q-learning for aggregated interference control in cognitive radio networks," IEEE Transactions on Vehicular Technology, vol. 59, no. 4, pp. 1823-1834, May 2010.

[25] M. Gen and R. Cheng, Genetic Algorithms and Engineering Design. New York, NY: John Wiley \& Sons, 1997.

[26] D. E. Goldberg, Genetic Algorithms in Search, Optimization, and Machine Learning. Reading, Massachusetts: Addison-Wesley, 1988.

[27] A. Konak, D. W. Coit, and A. E. Smith, "Multi-objective optimization using genetic algorithms: A tutorial," Reliability Engineering and System Safety, vol. 91, no. 9, pp. 992-1007, September 2006.

[28] E. Alba, Parallel Metaheuristics: A New Class of Algorithms. Hoboken, New Jersey: John Wiley \& Sons, 2005.

[29] S. Luke, Essentials of Metaheuristics (Lecture Notes). Department of Computer Science, George Mason University, February 2012. [Online]. Available: http://cs.gmu.edu/ sean/book/metaheuristics/Essentials.pdf

[30] C. R. Reeves and J. E. Rowe, Genetic Algorithms - Principles and Perspectives. Kluwer Academic Publishers, 2003.

[31] M. Tiwari and J. A. Harding, Evolutionary Computing in Advanced Manufacturing. John Wiley \& Sons, July 2011.

[32] G. Syswerda, "A study of reproduction in generational and steady state genetic algorithms," in Foundations of Genetic Algorithms, B. M. Spatz, Ed. Morgan Kauffman, 1991, pp. 94-101.

[33] U. Barth, "Wireless targets and challenges," GreenTouch Seattle Meeting, GreenTouch Mobile Communication Working Group, November 2011.

[34] S. Zhou, J. Gong, Z. Yang, Z. Niu, and P. Yang, "Green mobile access network with dynamic base station energy saving," in Proceedings of ACM MobiCom, vol. 9, no. 262,2009 , pp. 10-12. 
[35] R. M. Karp, "Reducibility among combinatorial problems," Complexity of Computer Computations, pp. 85-103, 1972.

[36] H. Kargupta, K. L. Deb, and D. E. Goldberg, "Ordering genetic algorithms and deception," in Parallel Problem Solving from Nature PPSN II. Springer, 1992, pp. $47-56$.

[37] "Self-optimizing networks: The benefits of SON in LTE," White Paper, 4G Americas, July 2011. [Online]. Available: http://www.4gamericas.org/ documents/Self-OptimizingNetworks-BenefitsofSONinLTE-July2011.pdf

[38] I. Viering, M. Dottling, and A. Lobinger, "A mathematical perspective of selfoptimizing wireless networks," in IEEE International Conference on Communications (ICC), June 2009, pp. 1-6.

[39] "Calibration for imt-advanced evaluations," Wireless World Initiative New Radio WINNER+, Tech. Rep., May 2010.

[40] S. Tombaz, P. Monti, K. Wang, A. Vastberg, M. Forzati, and J. Zander, "Impact of backhauling power consumption on the deployment of heterogeneous mobile networks," in IEEE Global Telecommunications Conference (GLOBECOM), December 2011, pp. 1-5.

[41] "Socrates: Self-optimisation and self-configuration in wireless networks," European Research Project. [Online]. Available: http://www.fp7-socrates.eu

[42] 3GPP TS 36.420, v10.2.0, "X2 general aspects and principles," October 2011.

[43] K. Son and B. Krishnamachari, "Speedbalance: Speed-scaling-aware optimal load balancing for green cellular networks," in IEEE INFOCOM, March 2012, pp. 2816-2820. 